\title{
MANUFACTURA TEXTIL Y COMERCIO EN MALLORCA, 1700-1830
}

\author{
CARLES MANERA \\ Universidad de las Islas Baleares
}

Los estudios sobre el campesinado mallorquín suelen presentar su vinculación casi exclusiva a trabajos puramente agrícolas, de forma que la inexistencia o la irrelevancia de las actividades no agrarias se admite como uno de los rasgos del mundo rural insular. Sin embargo, las variables demográficas constatan el crecimiento de la población, mientras las de producción certifican la notable recesión del aceite y los cereales - principales renglones de la economía mallorquina-, y un espectacular incremento de las cosechas de legumbres ${ }^{1}$. Estas informaciones, en apariencia contradictorias, plantean la

\footnotetext{
' Algunas ideas de este artículo se plantean también en C. Manera (1988c). En relación a las variables de producción, el aceite experimenta una baja muy acentuada, del índice 100 para 1750-1759 al 50 para 1800-1809, con la consecuencia de una disminución de las exportaciones (G. Davíu, 1983: 410; C. Manera, 1988 b: 32-126). Los cereales conocen también un retraimiento que va del índice 100 para 1700-1709 al 93,88 para 1800-1809 y 77,18 en 1810-1819 (I. Moll y J. Suau, 1985: 275). Por otra parte, la población insular crece en el siglo xviII, con unos rasgos característicos: la persistencia de una fecundidad matrimonial moderadamente elevada, unos cocientes de mortalidad infantil relativamente bajos y una caída de la mortalidad catastrófica. Se evidencian cambios en el comportamiento demográfico de áreas concretas (I. Moll, A. Segura y J. Suau, 1983; I. Moll y J. Suau, 1985: 254; A. Segura y J. Suau, 1984). Esto puede ser debido a: 1 . La diversificación de la producción. Mallorca dispone de otros géneros que pueden reemplazar al aceite en coyunturas y mercados determinados. La oferta exportadora es tímida pero patente, y se pone de manifiesto en las cifras comerciales, lo cual explicaría el descenso productivo y extractivo de la principal divisa insular. 2. El aumento de las cosechas no cerealícolas. La producción observa unas variaciones que cabe destacar: mientras los cereales, como se ha señalado, presentan una contracción, las legumbres anotan el índice 100 para 1700-1709 y 178,5 para $1800-1809$ (1. Moll y J. Suau, 1985: 275). El incremento es notorio, y manifiesta que la dependencia frumentaria puede ser superada al disponerse de otras producciones locales. En tal aspecto, J. Thirsk (1988) ha enfatizado este tipo de cambios en las economías campesinas, destacando sobre todo la búsqueda de cultivos alternativos al grano -comercializables y de autoconsumo: frutas, verduras- que permiten al campesinado la obtención de mayores réditos. 3. La existencia de actividades no agrarias, localizadas en núcleos precisos, que posibilitan trabajos aleatorios a sus pobladores (A. Segura y J. Suau, 1981). Los mercaderes son los principales articuladores de esta red manufacturera, como queda demostrado en M. Deyà (1987) y C. Manera (1988 b: 126-179). Los factores citados facilitan una explicación más plausible sobre la situación de una economía en principio supeditada a dos mercancías básicas, el aceite y los cereales, que, paradójicamente, sufren una producción decreciente y, en el caso de los despachos oleícolas, la remisión exporta-
} 
existencia de procesos de «reacción» ante las coyunturas críticas, permitiendo que los sectores sociales más afectados por las crisis de subsistencias afronten la escasez y el hambre en condiciones menos gravosas; así, puede entenderse que los índices poblacionales de determinadas zonas de la isla durante el Setecientos no respondan en absoluto a parámetros de declive económico ${ }^{2}$.

Uno de estos mecanismos de «resistencia» es la industria doméstica, organizada en parte por el capital comercial. Las inversiones de los pequeños mercaderes, destinadas a formar infraestructuras manufactureras, inciden directamente sobre la fuerza de trabajo gremial y segmentos del campesinado, a la vez que anexionan mano de obra femenina en el proceso de producción. Los agremiados eluden de esta manera la estrecha vigilancia corporativa, y los campesinos y las mujeres tejen o hilan a tiempo parcial. Los pequeños negociantes contribuyen a la sobreexplotación del campesinado, en una cadena en la que también se inserta la actuación de los grandes cargadores, toda vez que controlan algunas de las remesas de materias primas, despachadas a crédito a los primeros o directamente a los tejedores. Por su parte, los campesinos y artesanos pobres (conjunto social que padece con mayor intensidad las fluctuaciones de los productos básicos) pueden acceder a unos ingresos que complementan sus reducidos salarios ${ }^{3}$.

La filosofía ilustrada planifica el tipo de manufactura que cabe fomentar; se trata del modelo de «industria popular», dispersa, que ha de cumplir una doble función. En primer lugar, no modificar decisivamente las relaciones de producción, manteniéndolas en los márgenes fijados por la estructura económica del Antiguo Régimen. En segundo término, impedir la concentración

dora; sin embargo, la población no padece graves calamidades demográficas. Véase un planteamiento similar en E. Llopis (1986: 596-597).

${ }^{2}$ El impulso demográfico se produce por: a) La elevada natalidad, constante entre finales del siglo XVI y mediados del XIX. b) Los índices de nupcialidad, que siguen pautas distintas de comportamiento en función de la estructura de la propiedad, las actividades no agrarias, la comercialización de la producción agrícola y los condicionantes culturales. c) Las relaciones bautismos-matrimonios, que son altas para Mallorca: más del 4,54, llegando al 5,15 para el período 1700-1779. La media para 1760-1799 es de 4,70, similar a la de una región de Flandes, Le Vieuxbourg, que, con 5,12 (1766-1795), cuenta, además, con una importante industria de lino. d) Una baja mortalidad infantil: la media para 1720-1799 es 207,19 por 100 , inferior a la de otras zonas peninsulares. La tasa de crecimiento de la población mallorquina entre 1746 y 1857 se sitúa en 0,47 por 100 , parecida a la de Francia $-0,49$ por 100 - e Italia $-0,46$ por 100 - (A. Segura y J. Suau, 1984). Algunos estudios sobre zonas europeas determinan una fuerte relación entre crecimiento demográfico $e$ industria rural: véanse los casos de Flandes, Sajonia y Nottingham, donde la población del campo se multiplica aceleradamente, en comparación a los índices urbanos (J. de Vries, 1982: 118-120). Uno de los ejemplos más claros es el de las regiones montañosas de Zurich, con una población que se triplica entre 1634 y 1794, caracterizándose por su inclusión en la industria a domicilio ( $R$. Braun, 1978: 289-334; véase, también, Ch. Tilly, 1984).

${ }^{3}$ A. Segura y J. Suau (1982: 432-433); F. Mendels (1986: 246); Ch. Tilly (1983: 127-128). 
de trabajadores para evitar la canalización unitaria, en forma de revueltas similares a las de 1766 , del descontento que generan las crisis de subsistencias.

El análisis de la documentación sobre el trabajo realizado al margen de la jornada laboral en el campo, o la actividad desarrollada por los artesanos fuera de la entidad gremial, junto a las cifras calculadas sobre el comercio de manufacturas e inputs textiles - aspectos ya expuestos en recientes investigaciones - obliga a matizar y replantear el tema de los sectores no agrarios en la economía de Mallorca. Parece ser que éstos tienen una relevancia mayor que la supuesta, a la vez que explican comportamientos socioeconómicos particulares -una evolución diferente de la estructura de la propiedad, de las pautas demográficas y de los salarios ${ }^{5}$ - en los pueblos que disponen de una mayor diferenciación profesional.

Teniendo en cuenta las observaciones precedentes, el presente estudio se ordena en tres planos básicos. En el primero, se establece la importancia de los textiles y sus factores de producción en la estructura comercial mallorquina. En el segundo, se precisa el cometido de los comerciantes como vertebradores del mercado interior, y en cuanto a la formación de infraestructuras manufactureras, de forma que se resaltan sus conexiones con los diferentes grupos sociales ligados a este tipo de industria. Y en el último, se subraya la interrelación que puede existir entre la manufactura y algunas transformaciones económicas -concretamente, la progresiva especialización agrícolaen aquellas áreas con una actividad textil más dinámica.

\section{Comercio exterior $y$ textiles}

Las variables disponibles sobre exportaciones e importaciones mallorquinas determinan que los intercambios descansan respectivamente en dos mercaderías, el aceite y los cereales ${ }^{6}$. El resto de productos que integran la

4 C. Manera (1988 b); M. Deyà (1987). Consúltese, también, M. Bernat (1985, 1986). Estos estudios manifiestan la significación de los trabajos del lino y de la lana en la economía mallorquina de los siglos xviI y xvIII. F. Sevillano (1976: 537.552) patentiza la relevancia de los tejidos de lana en épocas anteriores, durante los siglos XIV y XV, cuya extracción permitía cubrir el déficit comercial mallorquín; a la vez que indica el cuidado extremo en vigilar la producción lanera, dados los fraudes consistentes en hacer pasar por mallorquinas las producciones textiles extranjeras. El auge de la manufactura textil en el XIV contrasta con la débil estructura aindustrial» de la segunda mitad del XIII, que, como ha apuntado A. Riera Melis (1986: 49-76), se vincula al autoconsumo; mientras que, en contraposición, el comercio exterior conoce una etapa expansiva.

s. Segura y J. Suau (1981).

- Se han trabajado los casi cien libros de la aduana del puerto de Palma correspondientes al siglo xviII, clasificados en el Arxiu del Regne de Mallorca (=ARM). Su sistematización ha permitido reconstruir las balanzas comerciales de los años 1701, 1704, 1720, 
balanza comercial, a pesar de que poseen valores bastante inferiores con respecto a los oleícolas y cerealícolas, no son desdeñables como elementos que deben trabajarse cualitativamente, ya que sugieren actividades productivas no circunscritas a un estrato meramente agrícola. En este sentido, los textiles constituyen un capítulo a considerar, habida cuenta que de sus cifras comerciales se desprenden matizaciones de gran interés. Es importante destacar lo siguiente:

a) Compras elevadas de materias primas.-Componen un apartado propio en las importaciones. Se introducen remesas de algodón, cáñamo, cueros, esparto, hierro, hilo, lana y, básicamente, lino. Cabe resaltar dos aspectos.

Primeramente, la fabricación de tejidos mixtos, fundamentalmente de lino y algodón, en aumento entre la población mallorquina si se tienen en cuenta las entradas de ambas mercancías, especialmente las de algodón. Estas son relevantes a partir de 1750 , siendo de escasa consideración en años precedentes: en 1754 llegan a la bahía palmesana unas 44.000 libras de peso, hacia 1770 se anotan 34.000 , a fines de siglo se descargan 18.000 y en los inicios del Ochocientos esta cifra fluctúa entre las 24.000 y las 30.000 libras. Estos guarismos contrastan con las 20 canas consignadas en 1704 y las 3.500 libras calculadas para 1720 .

En segundo lugar, la fibra más relevante es, indudablemente, el lino, pues supone entre el 45 por 100 y casi el 80 por 100 del total de materias primas depositadas en el puerto de Palma. Las cantidades asentadas en la aduana oscilan entre 10.000 y 80.000 libras de peso, evidenciando un progresivo crecimiento de su demanda. Los mayores registros se alcanzan entre 1705 y 1770 , mientras que las cantidades más ajustadas corresponden al último tercio y a los primeros años del siglo $\mathrm{xIx}$, hecho que puede obedecer a un incremento de la producción propia evaluada, a fines del Setecientos (1784), en unas 835.000 libras, entre lino (235.000) y cáñamo (600.000), elaboradas por unos 650 menestrales y 870 telares. Las cosechas son, pues, elevadas; un examen más profundo de su distribución entre las villas insulares certifica la penetración del capital mercantil en el ámbito rural. Así se explica que poblaciones con reducida producción de las citadas fibras con-

1754,1768 y 1787 . Se ha complementado esta fuente con otros fondos públicos, emplazados en dicho Archivo y en el Arxiu Municipal de Palma (=AMP) y el Arxiu Municipal de Felanitx (=AMF). Se trata, básicamente, de un importante número de expedientes gremiales textiles que informan sobre la producción, la organización laboral y el tráfico interior y exterior de la manufactura. Se ha utilizado también documentación privada -esencialmente sobre compras de materias primas y ventas de manufacturas, y la organización de los procesos productivos-, procedente de los archivos de cuatro importantes familias de comerciantes -Billón, Capó, Marcel y Mayol-. Por el momento, no se han localizado series fiables de entradas de cereales, lo que ha motivado su omisión en el presente análisis. 


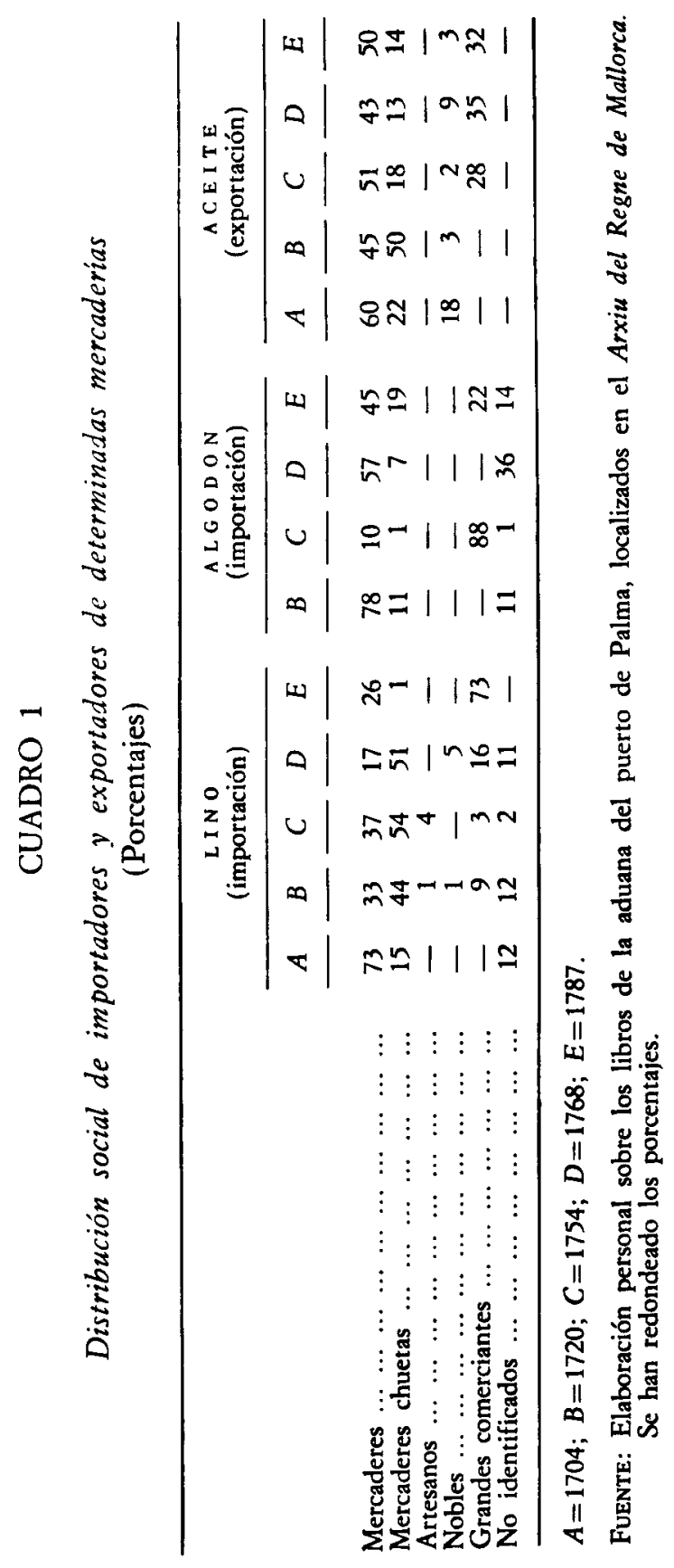


trasten con un colectivo de artesanos comparativamente importante; y, en el caso opuesto, que una elevada recolecta no se corresponda con un número reducido de menestrales. Esta falta de sincronización refleja la movilidad interior: los mercaderes y los agremiados ricos trafican con las partidas excedentarias de unas áreas y las canalizan hacia otras con bajas cosechas y un número considerable de fuerza de trabajo, comunidades que confían en la formación de una red distributiva que les permita obtener los factores de producción imprescindibles para la manufactura. Los pequeños comerciantes articulan, por consiguiente, la producción artesanal, y facilitan la integración del mercado, dado que éste absorbe materias primas y una parte importante de los géneros elaborados. Volveremos posteriormente sobre este punto.

Las importaciones generales de lino y de algodón señalan la concentración de las remesas en manos de distintos grupos mercantiles, toda vez que los porcentajes totales superan el 80 por 100. En el caso de la primera fibra, los mercaderes chuetas (descendientes de judíos conversos) abrevian los mayores indicadores; para el resto de pequeños y grandes cargadores se establecen unos guarismos más fluctuantes, mientras que artesanos y nobles alcanzan unas cifras muy reducidas (la remisión mercantil de estos últimos también se revela en su escasa participación en el tráfico oleícola). En relación al algodón, se acredita un claro interés por parte de los principales negociantes - con cantidades determinantes en 1754-, y una cierta regularidad porcentual de los mercaderes. Si se aplican los modelos de S. Chassagne $^{7}$, se concluye, por un lado, que las introducciones de la principal fibra utilizada por los trabajadores manufactureros, el lino, se acomodan al esquema triangular, es decir, el formado por comerciantes minoristas, mayoristas y menestrales, por ser los colectivos que controlan los cargamentos procedentes del exterior, con un vértice muy claro: el de los negociantes chuetas. Por otra parte, se genera una atomización en el apartado correspondiente a los envíos de textiles y mantas, sin una delimitación clara de quiénes son los principales cargadores, agravada por un abultado grupo de exportadores no identificados; estas características encajan en el tipo trapezoidal, integrado por pequeños comerciantes, tejedores, grandes firmas, negociantes extranjeros, emigrantes, etc.

b) Extracciones de manufacturas textiles.-Sintetizan entre el 4 por 100 y el 15 por 100 del total exportado. Entre ellas sobresalen los géneros de lana y los de lino. En los inicios del Setecientos, las mantas de lana y las telas - sobre todo las confeccionadas también con lana- constituyen apro-

' S. Chassagne (1981). X. Carmona (1984) ha reseñado para el caso gallego sus similitudes con los modelos de $S$. Chassagne. 
ximadamente el $8-10$ por 100 de los cargamentos registrados en la aduana de Palma. Esta tendencia se mantiene a lo largo del xviri, avalada por la importante producción local de materia prima. Esta se sitúa, a fines del Setecientos, entre los 6.000 y 8.500 quintales anuales, y nutre los 200-225 telares y 700-850 pelaires y tejedores censados en la isla, que fabrican unas 9.000 mantas — producto destinado casi íntegramente a la exportación-y otro tipo de efectos como birretes, buratas, enaguas, fajas, gorros, estameñas y sombreros. No obstante, a partir de 1720-1730, la lana compite con los trabajos de lino, y posteriormente, hacia 1750-1755, con los mixtos de lino y algodón. Tales caracteres permanecen hasta 1820 , en que el algodón empieza a adquirir una mayor significación.

Por otra parte, cabe acentuar la importancia de los años 1720-1760, período en el que parece marcarse una etapa de desarrollo artesanal en la isla que afecta igualmente otros sectores del trabajo «industrial». Por ejemplo, en 1720 las compras de acero (68 quintales), cueros y pieles (6.000 piezas) y hierro (2.400 quintales) significan el 22 por 100 de las importaciones, excluyendo las entradas de grano; y en 1754 esas mismas mercancías alcanzan magnitudes similares, incluso superiores, concretadas en 68 quintales de acero, más de 80 quintales y 10.000 piezas de cueros y pieles, y 8.000 quintales de hierro, que representan casi el 20 por 100 del total introducido, marginando siempre las partidas cerealícolas. El tipo de género resultante de la manipulación de estos inputs apenas se refleja en las exportaciones, de manera que es factible una primordial y casi exclusiva asimilación por parte del mercado interior mallorquín. Se plantea así la hipótesis de que esa coyuntura, favorable para la manufactura en general, sería más apreciable para la elaboración de textiles mixtos — con la adopción del algodón en los procesos de trabajo-, y quizá extensible a las tareas relacionadas con la construcción naval (fabricación de clavos y planchas) y la zapatería (las extracciones de zapatos son insignificantes: en 1754 se reducen a 34 pares, y en 1768 a 27; pero lo que cabe formular es el consumo interno de estas producciones cuyo desarrollo, aunque modesto, podría evitar compras en el exterior).

Esta paulatina consolidación de la manufactura no desagrada a los ilustrados mallorquines, quienes manifiestan una clara predisposición a incentivar las actividades textiles. Efectivamente, se advierte la influencia de Campomanes, concretamente de su Discurso sobre el fomento de la industria popular, y en particular de los párrafos sobre la utilidad de la industria dispersa, uno de los resortes que debe equilibrar el crecimiento económico, considerado como necesario, y una estabilidad política no menos indispensable. En definitiva, se defienden los esquemas de «progreso" que se encierran en 


\section{Importaciones de lino $y$ de algodón}

(En libras de peso)

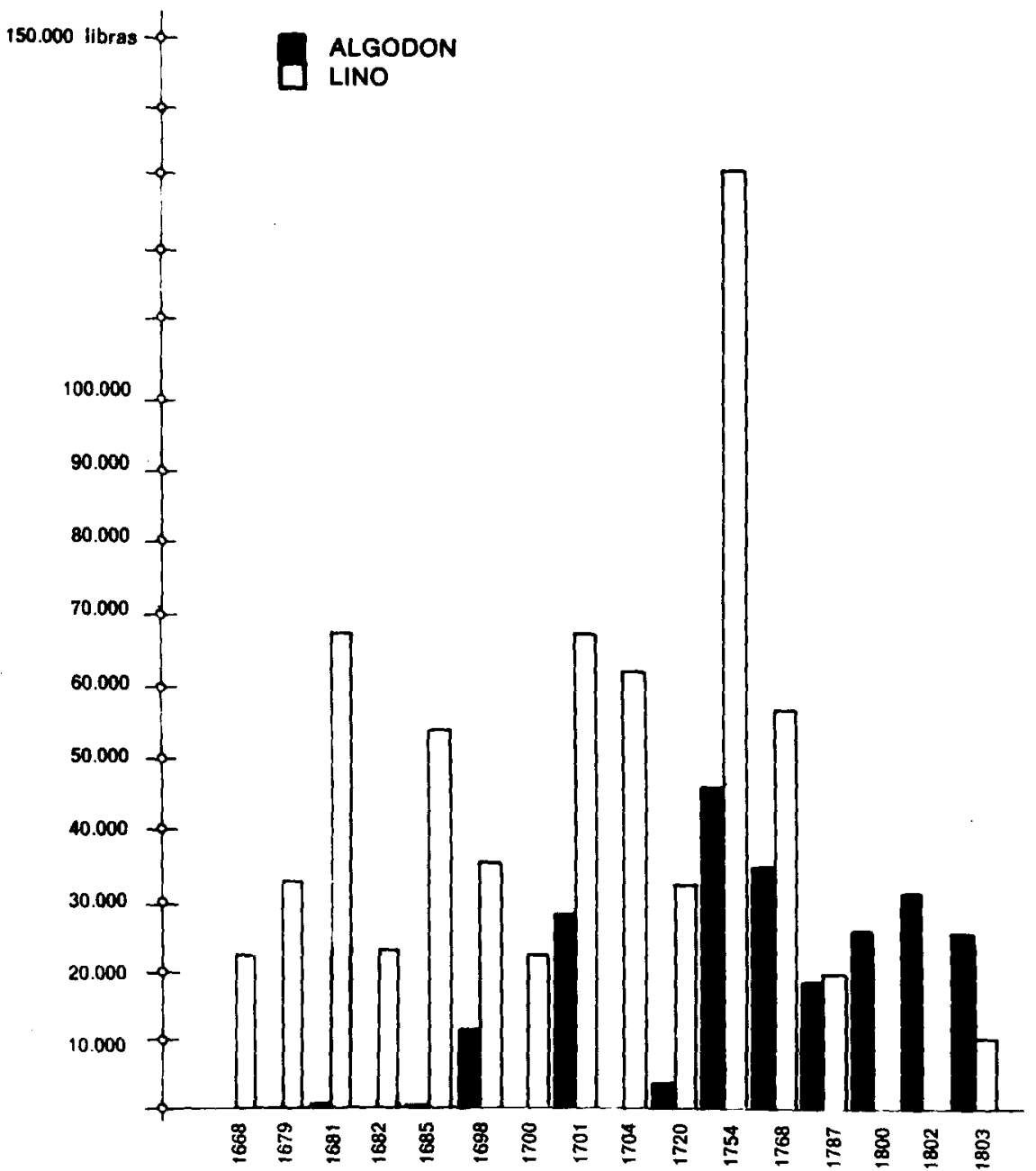

las coordenadas del Antiguo Régimen, cuyas estructuras se trata de preservar a toda costa ${ }^{8}$.

- Véase el interesante planteamiento de J. M. Delgado (1987: 25-40). Los textos de la ilustración mallorquina referidos estrictamente a la manufactura, y que cabe tener en cuenta por su interés, son la Memoria sobre las manufacturas de seda de la Isla de Mallorca (1784), escrita por Bernat Contestí, tesorero de la Sociedad Económica Mallorquina 
Exportaciones de mantas de lana

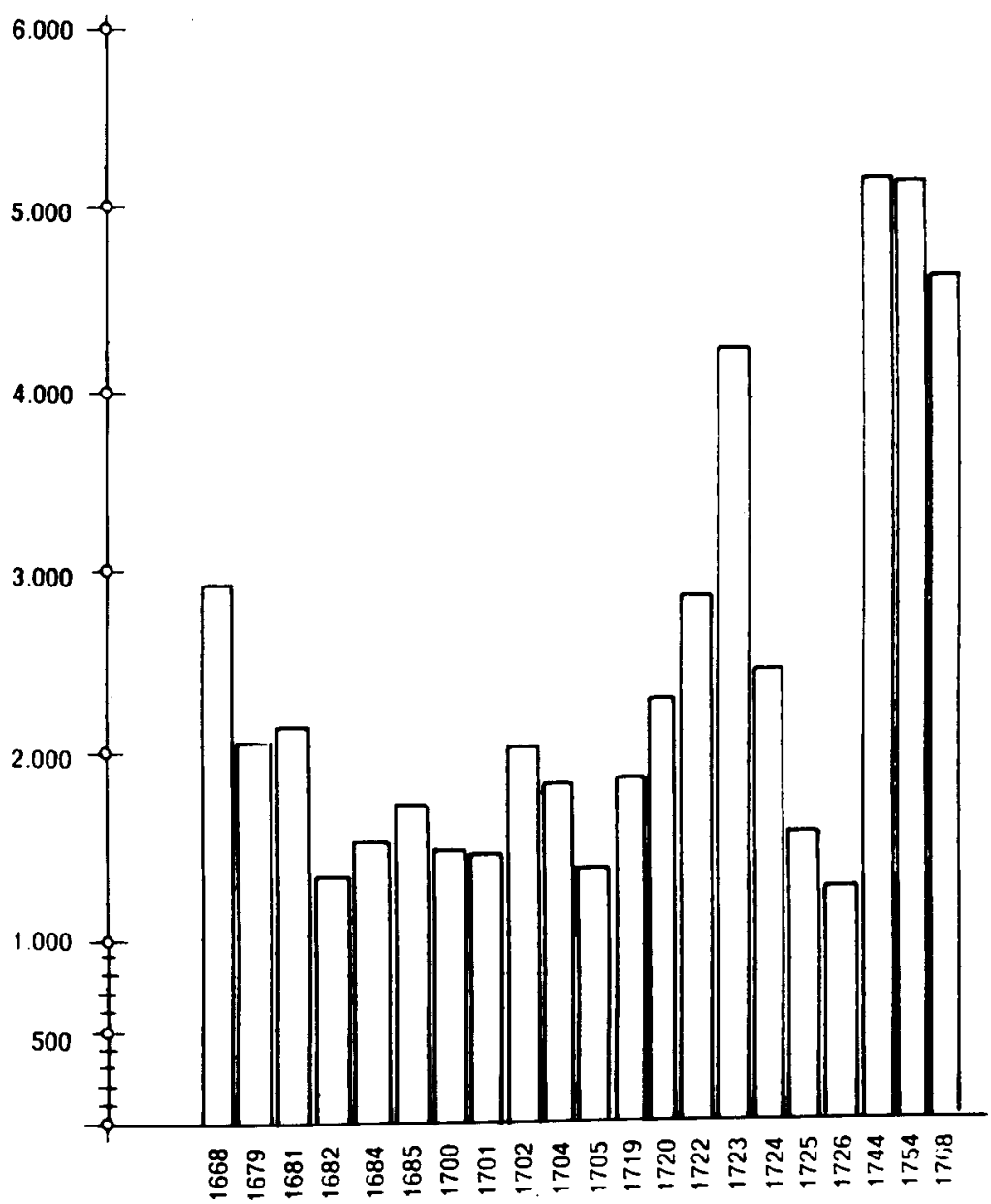

Los escritos de los reformistas isleños demuestran la noción precisa del tipo de manufactura que urge impulsar; en tal aspecto, unos puntos resumen la «teoría económica» ilustrada. En primer término, se indica que el trabajo textil es el complemento de las labores agrícolas; su objetivo no consiste en desbancar a la agricultura, sino que debe servir como un complemento

de Amigos del País; Memoria sobre los medios más eficaces para fomentar las manufacturas más útiles a esta Isla, y la Memoria sobre fábrica de indianas, ambas anónimas y redactadas en 1785. 


\section{CUADRO 2}

Exportaciones de mantas de lana por el Puerto de Palma

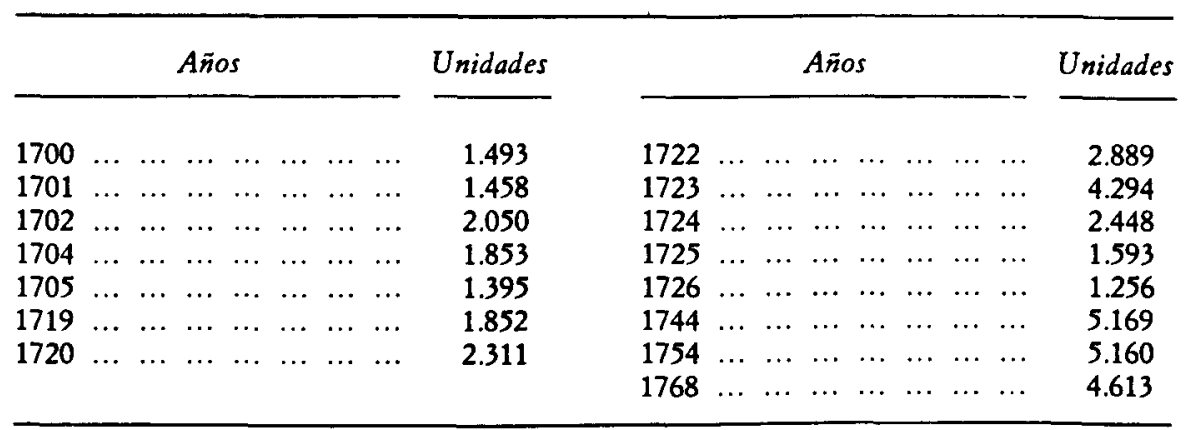

Fuentes: Elaboración personal sobre los libros de la aduana del puerto de Palma y la sección «Diputació» del Arxiu del Regne de Mallorca, núms. 923, 925-927, $929-931,1149,1161,1168$ y 1172.

\section{CUADRO 3}

Exportaciones por el Puerto de Palma

(Valores en lliures mallorquinas)

\begin{tabular}{|c|c|c|c|c|c|c|c|c|}
\hline & \multicolumn{2}{|c|}{1720} & \multicolumn{2}{|c|}{1754} & \multicolumn{2}{|c|}{1767} & \multicolumn{2}{|c|}{1768} \\
\hline & Valor & $\%$ & Valor & $\%$ & Valor & $\%$ & Valor & $\%$ \\
\hline Comestibles . ... ... & 155.882 & 85 & 339.808 & 84 & 358.499 & 94 & 138.241 & 82 \\
\hline Textiles $\ldots \ldots \ldots \ldots$ & 11.448 & 6 & 31.931 & 8 & 13.428 & 4 & 26.052 & 15 \\
\hline $\begin{array}{llll}\text { Viticultura } & \ldots & \ldots & \ldots\end{array}$ & 4.761 & 3 & 3.551 & 1 & 6.043 & 2 & 468 & - \\
\hline 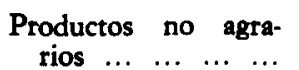 & 4.016 & 2 & 4.020 & 1 & - & - & 3.274 & 2 \\
\hline Legumbres $\ldots \ldots \ldots$ & 3.205 & 2 & 22.034 & 5 & - & - & - & 一 \\
\hline Otros $\ldots \ldots \ldots$ & 3.959 & 2 & 2.427 & 1 & - & - & 1.498 & 1 \\
\hline Total $\ldots \ldots \ldots$ & 183.241 & 100 & 403.771 & 100 & 377.970 & 100 & 169.533 & 100 \\
\hline
\end{tabular}

Fuentes: Para 1720, 1754 y 1768, elaboración personal sobre los libros de la aduana del puerto de Palma; para 1767, I. Moll (1977: 327). Se han redondeado las cantidades y los porcentajes: 1 lliura mallorquina $=13,3$ reales de vellón. 
CUADRO 4

Importaciones por el Puerto de Palma, menos los cereales panificables (Valores en lliures mallorquinas)

\begin{tabular}{|c|c|c|c|c|c|c|c|c|}
\hline & \multicolumn{2}{|c|}{1720} & \multicolumn{2}{|c|}{1754} & \multicolumn{2}{|c|}{1767} & \multicolumn{2}{|c|}{1768} \\
\hline & Valor & $\%$ & Valor & $\%$ & Valor & $\%$ & Valor & $\%$ \\
\hline Textiles $\ldots \ldots \ldots \ldots$ & 26.615 & 35 & 54.300 & 30 & - & - & 58.409 & 59 \\
\hline $\begin{array}{c}\text { Materias primas in- } \\
\text { dustriales } \ldots \ldots \ldots \ldots \\
\text { Materias primas tex- }\end{array}$ & 17.174 & 23 & 33.958 & 19 & 9.176 & 2 & 8.215 & 8 \\
\hline $\begin{array}{ccccc}\text { tiles } & \ldots & \ldots & \ldots & \ldots\end{array}$ & 7.286 & 10 & 31.277 & 17 & 34.838 & 8 & 13.764 & 14 \\
\hline $\begin{array}{l}\text { Cueros y pieles ... } \\
\text { Coloniales y espe- }\end{array}$ & 6.034 & 8 & 12.180 & 7 & - & - & 1.093 & -1 \\
\hline $\begin{array}{ccccc}\text { cias } & \ldots & \ldots & \ldots & \ldots\end{array}$ & 5.662 & 7 & 31.514 & 17 & 一 & - & 9.442 & 10 \\
\hline Comestibles $\ldots \ldots$ & 5.287 & 7 & 4.578 & 2 & 390.158 & 89 & 369 & - \\
\hline Otras manufacturas. & 560 & 1 & 10.109 & 5 & - & - & 5.326 & 5 \\
\hline $\begin{array}{lllll}\text { Otros } & \ldots & \ldots & \ldots & \ldots\end{array}$ & 6.465 & 9 & 5.277 & 3 & 5.096 & 1 & 2.416 & 3 \\
\hline Total ... ... ... & 75.083 & 100 & 183.193 & 100 & 439.268 & 100 & 99.034 & 100 \\
\hline
\end{tabular}

Fuentes: Las mismas del cuadro 2. En el caso de 1767 se estiman también las entradas cerealícolas, omitidas por los funcionarios de la aduana en los años restantes.

desarrollado esencialmente en el propio domicilio del campesino, con la recomendable participación de toda la familia. En segundo lugar, se prefieren las manufacturas bastas —obra de palma, medias de cáñamo y de lana, cordones y trabajos con paja-; es decir, mercancías con bajos costos de oportunidad, ya que se realizan cuando concluye la jornada en el campo y, en determinados casos - como puede ser la fabricación de gorros por parte de los pastores-, durante la misma. Por tanto, se priman los géneros confeccionados con «crudos territoriales» - lana, lino y cáñamo-, y secundariamente los realizados a partir de materias primas externas -algodón-, ya que éstas uno son del País y por lo mismo esta fábrica no da utilidad a la agricultura». Finalmente, se trasluce el principal sentido social de la industria así establecida: el control sobre una población necesitada de recursos suplementarios, organizada en un proyecto manufacturero nada contradictorio con las premisas socioeconómicas del Antiguo Régimen, que, sin desbancar las faenas agrícolas, actúa a la vez como inmovilizador de una mano de obra descontenta, potencialmente peligrosa durante las crisis de subsistencias. 
En los inicios del siglo XIX, esta clase de manufactura, idónea —según los ilustrados - para integrar la industria popular, está ya enraizada entre el campesinado y el artesanado mallorquín ${ }^{9}$, que siguen trabajando con cáñamo, lana y lino, y utilizan el algodón como mezcla. No se da, pues, un claro proceso de sustitución de las materias primas tradicionales por esta última, aunque las compras que se han documentado son, en algunos casos, de consideración ${ }^{10}$. Sin embargo, no se disponen de cifras, para toda Mallorca y durante los primeros años del Ochocientos, sobre la producción sectorial de manufacturas textiles, sus costos y destinos; tan sólo se ha podido reconstruir un «estado industrial» de Palma relativo a 1817 que, a pesar de su marginalidad y previsible inexactitud, presenta algunos datos de interés ".

En primer lugar, la mayor parte de la producción manufacturera se destina a satisfacer la propia demanda. En segundo término, se despachan en el mercado exterior los excedentes de unas producciones determinadas: el 17 por 100 de las manufacturas de madera, el 40 por 100 de las cerámicas y el 42 por 100 de los tejidos de lino; ahora bien, se constatan efectos elaborados prioritariamente para su venta exterior, como las botas (87 por 100), las mantas ( 100 por 100 ) y los objetos de vidrio ( 75 por 100 ). Por último, es difícil saber si la totalidad del proceso productivo se ejecuta en la capital, o si se trata de géneros acabados en la ciudad $-\mathrm{y}$ que figuran como manufacturados íntegramente aquí-, pero iniciados en las zonas rurales; al respecto, debe destacarse que en 1816 los tejedores de lana de Palma elevan una queja al "Real Consulado de Mar y Tierra» por el incumplimiento sis-

- La Comisión de Industria de la Sociedad Económica Mallorquina de Amigos del País expresa, en 1800, que ren varios Pueblos de la Ysla bay alguna industria de bastante utilidad para ocupar la gente en los dias lluviosos», indicándose la obra de palma, los gorros, las cuerdas de esparto y la hilatura de cáñamo, estambre y lino. Se certifica que ua excepción de las obras de palma (...) las demás se hacen de noche y en días lluviosos, sin incluir los gorros de lana (...) que trabajan regularmente los Pastores mientras apacientan sus ganados». Las importaciones de materias primas a comienzos del XIX -entre 1800 y 1804 - notifican compras irregulares, pero constantes, de elementos básicos para el funcionamiento manufacturero; se observan entradas de algodón (entre 24.000 y 30.000 libras de peso), cáñamo (entre 1.000 y casi 30.000 libras) y lino (8.000 libras): ARM, Sociedad Económica Mallorquina de Amigos del País $(=\mathrm{SEMAP})$, caja 26, expediente núm. 7. Las cifras citadas son un cálculo personal sobre la contabilización de las entradas y salidas de navíos y sus respectivas cargas, consignadas en el Semanario Económico, publicación de la SEMAP.

${ }_{10}$ Esta sustitución se aprecia, por ejemplo, en Finlandia (P. Virrankoski, 1963). En relación a otras fibras, el reemplazamiento de la seda por el algodón se constata en la Manresa del XIX (Ll. Ferrer, 1986: 30-32).

11 AMP, legajo 883, expediente núm. 6567. Se trata de un interrogatorio elaborado por la Junta de Aranceles de Rentas, que pretende averiguar el número de fábricas existentes en Mallorca y wel grado de concurrencia mercantil en que se ballan las manufacturas nacionales respecto a las extrangeras». El intendente general traslada el cuestionario al Ayuntamiento de Palma, que recoge únicamente la información proporcionada por los gremios capitalinos, de forma que se ofrecen referencias muy concretas sobre el trabajo textil. 
temático de sus ordenanzas corporativas, que establecen que las piezas fabricadas en las villas y nuevamente manipuladas en la capital paguen la cuota correspondiente a dicho gremio. Ello es sinónimo de que una producción significativa, imposible de cuantificar en estos momentos, entraba en la ciudad para ser rematada, y no estaba sometida al control de las instituciones profesionales capitalinas.

Estas variables señalan una etapa favorable para la industria urbana que puede englobar el período $1808-1820$, a la vez que se sugiere una moderada recesión de la rural. Unos puntos concretos complementan esta hipótesis:

1. El consumo explicitado de manufacturas palmesanas por parte del agro isleño. Los datos de los que disponemos no permiten todavía ir más allá de unas primeras suposiciones. Por una parte, la posible caída de la producción manufacturera rural, que implicaría su supeditación a la trabajada en el casco urbano; por otra parte, el importante incremento del consumo en las áreas rurales, con una producción propia teóricamente insuficiente para satisfacer la demanda. En una primera apreciación, parece más plausible la primera de las alternativas citadas.

2. Las cifras sobre los ingresos de los gremios de tejedores de lino y cáñamo corroboran la «recuperación industrial» de Palma entre 1809 y $1819^{12}$. Prácticamente el 45 por 100 de las entradas de dichas corporaciones corresponden a la capital, frente al 55 por 100 de las comarcas rurales; para 1827-1828 estos porcentajes son, respectivamente, 34 y 66 por 100 , de manera que se observa la clara bajada urbana, tendencia que se mantiene en $1828-1829$ ( 37 y 63 por 100) y $1831-1832$ (36 y 64 por 100). A similares conclusiones se llega con los datos sobre nuevos maestros: entre 1805 y 1818, los de Palma representan el 37 por 100, mientras los de las áreas rurales alcanzan el 63 por 100; esta progresión cambia a partir de 1820, a pesar de que del total de los nuevos profesionales, el 16 por 100 corresponde a la capital y el 63 por 100 a las villas.

3. La cronología establecida coincide con la presencia catalana en Mallorca a raíz de la guerra de la Independencia. Aunque se ha minimizado, desde el punto de vista económico, el papel de los catalanes en la isla ${ }^{13}$, los intercambios que estimulan confirman un dinamismo portuario poco conocido en épocas anteriores. Sobre este aspecto, únicamente se han tomado como referencia los contactos isleños con el mercado americano. El tráfico entre Mallorca y las colonias se dispara a partir de 1808 , y, básicamente, entre 1812 y 1814, gracias a las gestiones de los comerciantes catalanes.

12 Recojo estos datos del trabajo de M. Deyà (1987).

${ }^{13}$ Consúltense los argumentos de Ll. Roura (1985). 
En Palma se cargan aguardientes, vinos y jabón, géneros tradicionales destinados a los mercados ultramarinos, a los cuales se suma la sedería. Estos cuatro renglones significan el 83 por 100 de las extracciones, mientras que con porcentajes más reducidos se encuentran otros efectos como sombreros, medias, indianas y papel. Estas producciones se trabajan en Mallorca, ya que se consigna su lugar de fabricación en los casos en que las remesas son de elaboración ajena a la isla; así, pues, se manifiesta la instalación catalana en la isla de talleres textiles y alambiques, un significativo tejido «industrial» que parece desmontarse con la firma de la paz. No obstante, los datos posteriores a 1814 indican la pervivencia de unas actividades artesanales que se concretan, por ejemplo, en envios de sedería y papel hacia América desde la rada mallorquina. Las sumas relativas a las mercaderías que fueron objeto de tráfico, por parte de los catalanes durante el conflicto napoleónico, señalan la existencia de una «nueva» infraestructura manufacturera, lo cual implica el aprendizaje de los mallorquines en relación a técnicas productivas practicadas en aquellos años críticos, principalmente las vinculadas a los trabajos de seda y la fabricación de papel, totalmente irrelevantes a fines del Setecientos. Esto puede justificar la positiva coyuntura de la industria urbana, pues los principales centros productores se disponen en la capital y/o dependen de ella ${ }^{14}$.

Estos datos muestran la significación de Palma como núcleo de producción y de consumo manufacturero dufante el primer tercio del siglo xIX - sin que se dé un proceso de concentración importante de los talleres

" Las primordiales mercancías, no agrarias, exportadas a América desde el puerto de Palma entre 1813 y 1817 se resumen, valoradas en reales de vellón, en el siguiente cuadro:

\begin{tabular}{|c|c|c|c|c|c|}
\hline & 1813 & 1814 & 1815 & 1816 & 1817 \\
\hline 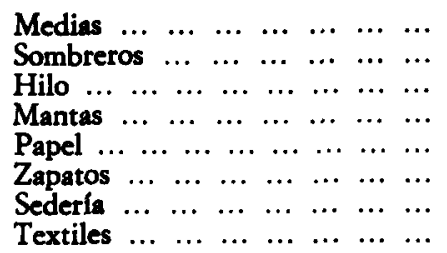 & $\begin{array}{c}21.072 \\
42.898 \\
16.605 \\
12.600 \\
54.430 \\
168.930 \\
-\end{array}$ & $\begin{array}{r}21.488 \\
8.424 \\
2.400 \\
\overline{24.800} \\
101.228 \\
-\end{array}$ & $\begin{array}{r}1.250 \\
7.200 \\
15.002 \\
\overline{-} \\
17.800 \\
6.030 \\
53.533 \\
-\end{array}$ & $\begin{array}{r}7.200 \\
15.000 \\
29.950 \\
6.960 \\
16.920 \\
4.720 \\
44.306 \\
21.146\end{array}$ & $\begin{array}{l}\bar{Z} \\
2.410 \\
\overline{-} \\
1.450 \\
13.116\end{array}$ \\
\hline
\end{tabular}

FUENrE: Elaboración personal sobre los datos del Archivo General de Indias, «Indiferente General».

L1. Roura (1985: 248, nota 261) presenta algunas autorizaciones del «Real Consulado de Mar y Tierra» de Mallorca a fabricantes y comerciantes para constituir diversas empresas, como tiendas de paños, fábricas de tejidos de algodón y seda e incluso un consorcio para estampar indianas. Por otro lado, E. Fernández de Pinedo $(1980: 111)$ sugiere que el relativo declive textil catalán entre 1812 y 1833 debió favorecer una cierta transformación del artesanado en otras zonas. 
dedicados a las labores industriales--, a la vez que enclave desde donde se organiza parte de los canales distributivos que ayudan a articular el mercado interior, sin restar la decisiva significación de las zonas rurales ${ }^{15}$.

\section{Organización productiva y capital comercial}

Los procesos descritos confirman la aplicación de las teorías ilustradas, que dominan los planes «industriales» en la isla durante las primeras décadas del Ochocientos. Sólo una pieza no parece encajar en la idea global de los Amigos del País: el papel de los comerciantes, marginados, al menos en la letra impresa, de la fase de la producción. Esta situación no se corresponde ni mucho menos con la realidad. Los mercaderes protagonizan, en el marco de la manufactura, una posición clara: por un lado, gestionan las entradas de materias primas; por otro, intervienen en la negociación definitiva de los géneros acabados. Sus actuaciones afectan a diferentes sectores de la economía e involucran en ellos a otros colectivos sociales. Este planteamiento se pone de manifiesto en los siguientes aspectos:

- La formación de capital. Los comerciantes mantienen un importante control sobre el capital circulante en el mercado, ya sea en créditos, en hipotecas o en numerario ${ }^{16}$. Este control se verifica de dos maneras. En primer término, los grandes cargadores pueden acaparar los mecanismos crediticios y ejercer como prestamistas a diferentes grupos sociales - nobleza, campesinado-, con los que se crean situaciones de endeudamiento progresivo. En segundo lugar, los negociantes disponen de materias primas - colocadas a pequeños mercaderes y a artesanos, generalmente a crédito-, y coloniales - géneros que a su vez se reexportan a otras zonas, como por ejemplo la costa italiana, cuando se satura la demanda interior-. Por otra parte, ejercen un monopolio sobre los productos básicos, explicable por los arrendamientos, desde comienzos del Setecientos, de tierras cerealícolas y oleícolas a la nobleza, que percibe rentas monetarias y en especie; y por las constantes compras de granos en el exterior ${ }^{17}$.

- La infraestructura comercial y la articulación del mercado. El establecimiento de una red exterior de colaboradores con los que sostiene un con-

15 El papel de las ciudades como centros dinamizadores de la economía se ha tratado en recientes trabajos: J. Maluquer de Motes (1985: 18-22); G. Galasso (1985: 22-27); G. Dragon (1985: 10-13); L. Gambi (1985: 12-18); A. Wyrobisz (1986: 6-13). Cabe consultar, también, las contribuciones más recientes - que recogen planteamientos generalesde J. de Vries (1987: especialmente 15.28 y 309-318) y P. Bairoch (1988).

${ }_{16}$ Se sigue la interpretación de E. J. Nell (1984: 78-80) en relación al ascenso socioeconómico de los comerciantes.

17 I. Moll y J. Suau (1979: 140-145); C. Manera (1984). 
tacto permanente, suministra al gran cargador la disponibilidad de un detallado conocimiento sobre las fluctuaciones de los mercados. El poder de esta información facilita un firme control del propio mercado, proceso en el cual se insertan las operaciones desarrolladas por el principal organizador del aparato manufacturero, el pequeño empresario. Este último traslada las materias primas de una villa a otra - de manera que se impulsa la división geográfica del trabajo, con sus delimitaciones laborales-, distribuye y racionaliza el proceso productivo, recoge la manufactura y la despacha en el interior o la canaliza hacia el exterior. Esta versatilidad, ya reflejada en páginas precedentes, indica a la vez la estrecha relación entre los mercaderes modestos y las firmas más importantes; estas últimas proporcionan las materias primas y los intermediarios seguros para las ventas de las manufacturas en el exterior, y complementan las líneas distributivas que los primeros poseen ${ }^{18}$.

Los negociantes, con su intervención en el ordenamiento de la fuerza de trabajo, infringen constantemente las ordenanzas de los gremios, sobre todo las de los tejedores de lino, de manera que son frecuentes los litigios entre ambas corporaciones profesionales. Estos expedientes notifican la significación del trabajo realizado sin contar con las disposiciones gremiales, y la capacidad de los comerciantes como organizadores de la manufactura rural, en la que coordinan a los sectores sociales más débiles. Ello se materializa en el hábil control que aquéllos tienen sobre las materias primas y sobre la mano de obra utilizada para su transformación.

Estos empresarios ignoran las reglamentaciones que conceden a los gremios el monopolio casi exclusivo de los inputs textiles, de forma que éstos son adquiridos fraudulentamente con la intención de distribuirlos con la mayor celeridad. De esta manera, surge una base productiva que se encuentra igualmente al margen de la tradicional estructura profesional. El caso más claro, que creará fuertes controversias judiciales, es el de la inserción de las mujeres -como elementos centrales de la hilatura - en los planes manufactureros de los mercaderes. Esa circunstancia motiva denuncias constantes por parte de la cúpula artesanal, inquieta ante la paulatina construcción de un aparato productivo paralelo, dominado por los pequeños cargadores. Este temor se expresa claramente en dos sentidos:

13 Esto puede constatarse en las frecuentes transacciones que unifican los diferentes colectivos mercantiles, reflejadas en los libros contables - principalmente en los de cuentas corrientes de clientes- de Antonio y Claudio Marcel y de Blas Billón. Véanse Arcbivo Casa Marcel, «Libros Contables», I (núm. 1), II y III; ARM, «Audiencia. Pleitos», II-B-94-12. 
1. La movilidad del capital mercantil. Los mercaderes disponen de un amplio número de trabajadores por cuenta propia en diferentes lugares, lo que evidencia la circulación de materias primas y la transacción con mercancías fabricadas soslayando las pautas gremiales; es una prueba convincente que explica el recelo de los dirigentes artesanales a la creación de fisuras en sus respectivas organizaciones. Los negociantes controlan sumas de materia prima bien mediante la conexión con un gran comerciante, que la importa desde regiones productoras y la despacha a crédito; o a través de una compra directa, ya en el exterior, con el apoyo de un sobrecargo que culmina la gestión, ya en el interior, infringiendo la normativa en relación a los sistemas de venta de cáñamo y lino en los mercados locales. Los propietarios de las citadas fibras deben demorar tres horas - desde las 8,00 hasta las 11,00 de la mañana- el despacho público de dichos géneros, concretamente a los interesados que no pertenecen a las organizaciones gremiales, con la finalidad de que en ese tiempo los agremiados compren las cantidades necesarias para su trabajo. Sin embargo, los mercaderes rompen con frecuencia estos estrictos límites, y contraen remesas de inputs antes del periplo estipulado, para dispersarlas posteriormente, iniciándose así los procesos productivos. Esta fluidez, incentivada por una organización precisa de las diferentes fracciones del complejo manufacturero - pequeños almacenes, redes de aprovisionamiento, mano de obra-, justifica las fracturas que va creando la estrategia del capital comercial en el seno de las instituciones artesanales.

2. Los cambios que puedan provocar los mercaderes en el proceso de producción. El trabajo textil se relaciona a la pervivencia de las distintas corporaciones; ello se traduce en una clara escrupulosidad por vigilar tanto los productos que se elaboran como los instrumentos necesarios para tal fin, ya que el control de la manufactura y de los medios de producción induce a asegurar entradas de numerario en las arcas gremiales. En este sentido, la limitación al número de telares dificulta el desarrollo de una producción más dinámica, dado que los maestros no pueden tener más de tres y las mujeres más de uno. Así se establece un sólido monopolio que dificulta el trabajo «libre», bloqueado por las cláusulas reglamentistas. Ahora bien, lo que éstas dicen no implica forzosamente su cumplimiento. La existencia de telares no declarados, con la intención de rehuir las represalias del gremio y los gravámenes fiscales, constituye un ejemplo representativo de la actitud del artesanado ante sus propios códigos jurídicos, burlados en muchas ocasiones merced a las conexiones existentes con los mercaderes ${ }^{19}$. Se plantean

19 Este hecho está documentado para finales del Seiscientos, al indicarse que los maestros tejedores no deben esconder los telares, penalizándose con 2 lliures si se descubre tal infracción: ARM, «Presidencials Decrets», 1691-1693, folio 575. E. Labrousse (1970: II, 546-547) destaca para Francia las limitaciones de las cifras establecidas oficialmente, y se- 
transformaciones significativas en el proceso de producción, toda vez que el objetivo que se persigue no es la mejor calidad de la manufactura, sino que ésta satisfaga una demanda determinada - principalmente interior, pero también externa - que solicita géneros bastos - de lana, lino y mezcla de algodón-, consumidos por las capas populares.

Así, pues, las cifras comerciales y los datos sistematizados sobre producción y formas de organización del trabajo indican la extensión en Mallorca de actividades textiles cuya importancia para las economías campesinas no debe ser ya ignorada. Se puede establecer una hipótesis sobre la evolución de dicho sector económico durante el siglo xviII hasta el primer tercio del XIX, en la que se delimitan cinco grandes fases:

1. 1700-1750. Se mantienen los rasgos heredados de fines del Seiscientos. Sobresalen dos elementos: en primer lugar, el contraste entre la importancia de los géneros de lana y la escasa significación de los de algodón, que se importa en cantidades apenas testimoniales; en segundo, el progresivo avance de las manufacturas de lino desde 1715-1720, que se convierten en un producto competitivo, de manera que comparten, junto a las mercaderías laneras, el grueso de las remesas textiles insulares.

2." 1750-1770. Se manifiesta la preponderancia paulatina del lino, junto a la lana. Las mantas conocen un fuerte impulso, motivado por una regular demanda exterior (litoral peninsular, mercado regional, puertos italianos y franceses). Se distinguen dos aspectos: el incremento general de la actividad manufacturera en Mallorca, situación que engloba tanto las labores textiles como las que afectan a otras facetas artesanales - producciones con cueros, pieles y hierro-; y la utilización de algodón —que se introduce en la isla en cantidades destacables - como primordial mezcla del lino.

3." 1770-1800. Se destacan tres factores. Primero, la extensión de las manufacturas de cáñamo y lino; se incrementa el consumo de cáñamo, hasta el punto de que la cosecha local no es suficiente para avituallar la fuerza de trabajo dedicada a su manipulación, lo cual comporta su adquisición en el exterior. Segundo, el mantenimiento de los trabajos de lana. Y tercero, la utilización continua del algodón como mezcla, si bien se observa una reducción de sus importaciones a fines de siglo y su transitoria recuperación hacia 1802.

ñala la existencia de un «espiritu de insubordinación» que se concreta en el desconocimiento intencionado de los reglamentos, lo cual significa que una cantidad considerable de piezas de telas, por ejemplo, escapan al control burocrático. Además, los artesanos declaran la situación de sus negocios en función de la marcha de los mismos. Esto encaja también en Mallorca, si se tienen presentes las informaciones de los numerosos expedientes gremiales revisados. 
4..$^{a}$ 1800-1820. Se caracteriza por la importancia de la industria urbana, sobre todo desde 1808 , al tiempo que puede apuntarse una pérdida transitoria de los espacios rurales, abocados a consumir grandes partidas de producciones fabricadas en la capital. El cáñamo, la lana y el lino son las fibras de los tejidos insulares.

5. 1820-1840. Se comprueba el estancamiento — pero no el retrocesodel trabajo artesanal urbano. El algodón empieza a tener una significación propia, seguido de un período expansivo hacia 1840; y una paulatina recuperación de las actividades rurales, en las que deben incluirse las áreas rústicas del término de Palma. Las últimas investigaciones geográficas sobre formaciones parcelarias en Palma ofrecen unas sugerentes interpretaciones ${ }^{20}$. El desplazamiento a la capital de jornaleros y artesanos desde 1835 -paralelo al aumento de la población-, con el objetivo de trabajar en la manufactura, exige un crecimiento urbano de difícil desarrollo en el marco de las murallas de la ciudad. Se producen, entonces, pequeñas parcelaciones (establiments, sometidas a censo enfitéutico) en las áreas que rodean la urbe, siendo las más frecuentes, en las primeras décadas del Ochocientos, las mixtas agrícola-residenciales, calificadas por una economía familiar que combina el cultivo de un trozo de tierra con el trabajo agrícola jornalero y artesano, o con las labores enmarcadas en la industria doméstica.

Un Informe sobre el estado industrial de Mallorca en $1829^{21}$ permite cotejar, aunque tal vez algo superficialmente, lo que se acaba de exponer. Las estadísticas que se recogen en esta documentación son incompletas, y justamente la notificación de esta deficiencia por parte del funcionario posibilita una orientación sobre la situación manufacturera, habida cuenta que no se inscriben, según se indica, «un gran número de telares, principalmente de Listados $y$ otros tejidos de bilo, de algodón y de lana que se ballan establecidos asi en la capital como en la parte foránea»; igual sucede con las fábricas de aguardiente y con «una infinidad de establecimientos de varias clases de industria; todos los cuales parece no deben contarse como fábricas porque no es continuo su trabajo, su producto es de poca consideración». Esto confirma la fijación, en el primer tercio del siglo xix, de una importante industria dispersa que se desarrolla a tiempo parcial, prolongándose las características conocidas para el siglo anterior ${ }^{22}$. Igualmente, la dinami-

${ }^{20}$ Sigo aquí a M." A. Carbonero (1987: 49-66). Véase, también, V. M. Rosselló Verger (1982: 45.52), quien señala un paralelismo entre las pequeñas parcelaciones y los inicios de la industria zapatera en Llucmajor - uno de los antiguos centros textiles-a comienzos del siglo XIX (cfr. p. 47).

21 ARM, «Junta de Comercio», expediente núm. 6.

22 Podría ser que, junto a los trabajos textiles, los habitantes de los establiments del término de Palma se dediquen a las primeras fases del proceso productivo de los zapatos, 
zación de esa infraestructura manufacturera parece mantener una estrecha relación con otros cambios operados en las estructuras económicas de los municipios más activos en los trabajos textiles, como se verá a continuación.

\section{Transformaciones económicas zonales. \\ Textiles y especialización vitícola}

Durante el Setecientos, Mallorca conoce el progresivo incremento de villas que se dedican a determinadas producciones agrarias, diferentes de las tradicionales. En esos pueblos coexisten la especialización agrícola y la fabricación de manufacturas textiles, de manera que en ellos se refrenda una mayor diversificación de recursos, fruto de transformaciones concretas en la economía agraria. Uno de los casos más significativos es el de Felanitx, municipio situado en el sureste de la isla, cuya población domina la fabricación de aguardientes. Dos rasgos claves se detectan en su economía a fines del xvin e inicios del nuevo siglo:

1. Una tímida, pero evidente, diversificación de la producción, junto a una clara dedicación a la viticultura. Entre 1794 y 1820 , los informes consistoriales detallan la existencia de algarrobos, higueras, árboles frutales, almendros y, sobre todo, viñedos. De todos ellos, sólo se comercializan las almendras y los derivados de la viticultura, principalmente el aguardiente. De las 6.600 cuarteras de almendras producidas, 6.500 se canalizan hacia el mercado extralocal. Por su parte, de un total de 150.000 arrobas de vino y de 30.000 quartines de aguardiente, se negocian 120.000 arrobas y 29.750

ya que las labores de cosido de las piezas de piel se ejecutan en el marco domiciliario; véase C. J. Cela Conde (1979: 81-85). Por otra parte, los datos que ofrece el archiduque Luis Salvador (1984: II, 53; este aristócrata fue un estudioso apasionado por la historia, la geografía y la cultura de los archipiélagos que, con una minuciosidad extrema, elaboró una obra monumental sobre las Baleares, de consulta obligada para los que investigan sobre la historia contemporánea de las islas), referentes a la segunda mitad del Ochocientos, refuerzan la idea de la existencia de una manufactura textil importante: las telas de lino y las mantas son, en este sentido, las mercaderías más características, exportándose el 50 por 100 de la producción de las primeras y el 80 por 100 de las segundas. Además, wen todos los pueblos bay algún tejedor que tiene un telar en su casa y alterna las tareas del campo con el tejer. Si se suman éstos a los que trabajan en las fábricas se obtiene el numero de 3.000 y se contabilizan 2.000 telares". Estas informaciones complementan las de P. Madoz (1848: XI, 124), quien sefiala el aumento de los intercambios comerciales de Mallorca, sustentados en las exportaciones de aguardiente, almendras, cítricos, habas, higos, lino, aceite, alcaparras, tejidos de lino-seda y lino-lana, y las importaciones de cereales, coloniales, esparto, paños y telas finas. En ambas fuentes se notifica que la actividad textil no es menospreciable, de forma que, siguiendo la tendencia del siglo xvi1, se convierte en complemento de las labores agrícolas entre los sectores campesinos más empobrecidos, y un capítulo a destacar en los cargamen. is efectuados en los puertos insulares. 
quartines, respectivamente. Las principales mercaderías de la economía mallorquina - los cereales y el aceite - son deficitarias: la urgencia frumentaria se cifra en 11.500 cuarteras de trigo, cebada y avena, mientras la oleícola se calcula en 6.200 «medidas». La producción media de grano es de unas 20.000 cuarteras anuales y la de aceite de 600 «medidas». Esta directriz se mantiene hacia 1820; sigue faltando trigo y aceite, mientras se elaboran 36.000 quartines de vino, de los cuales 20.000 son para destilar y vender en Palma y las zonas rurales, como pago de las remesas cerealícolas y oleíferas. Se verifica, pues, la especialización en la viticultura, especificada en los porcentajes de tierras dedicadas a su cultivo, el $36-46$ por 100 entre 1800 y 1820 , con un artículo comercializable: el aguardiente ${ }^{23}$. Este licor cuenta con dos tipos de demanda efectiva:

- En el mercado interior, que solicita cantidades muy regulares, poco fluctuantes, que contrastan con las bruscas oscilaciones de las ventas exteriores; es decir, se trafica sólo con los excedentes. No estamos ante una mercadería fabricada exclusivamente para su distribución extrarregional.

- Entre los mercados exteriores, el aguardiente es un género-muy valorado en el americano. Sin embargo, no es éste su principal punto de consumo. Las variables de los envíos a las colonias, desde 1782 hasta 1800, revelan que los mercados ultramarinos absorben un máximo del 18 por $100 \mathrm{del}$ total de las extracciones del citado efecto. Además de los puertos transatlánticos, cuatro ámbitos canalizan las remesas vitícolas: los centros peninsulares conectados con estos últimos - Cádiz y Canarias-, los circuitos mediterráneos clásicos en los intercambios insulares -básicamente los de las fachadas ligur y provenzal-, las demandas regionales - Ibiza y Menorca- y las radas norteatlánticas - con la de Amsterdam a la cabeza-.

La producción de aguardiente en Felanitx y su negociación determina la formación de grupos productores-mercantiles en los que no se identifican los nombres de las firmas más solventes o del colectivo chueta. Aun así, son muy probables estrechas conexiones entre todos ellos, habida cuenta que entre 1783 y 1788 casi el 70 por 100 del aguardiente que se exporta por el puerto de Palma procede de la villa citada, seguida por otras que, a un nivel inferior, alcanzan asimismo una clara especialización vitícola: Porreres $(12,82$ por 100), Manacor (5,92 por 100), Campos (4,21 por 100), Llucmajor (4,17

${ }^{23}$ AMF, legajos $130, \cdot 217,334,357-\mathrm{A}$ y 451 . Se afirma que "vino ay mucho, abrá año en que se cogerán trenta mil cargas de ubas cada una de tres quintales pero no es de muy buena calidad, ni todo sufre el transporte por el mar, y es preciso convertirlo en Aguardiente que suele ser especialisimo y se baze en grande acopio». No es extraña la escasez cerealícola: las comarcas que profundizan su especialización vitícola conocen una demanda creciente de subsistencias, lo cual activa el comercio interior (J. Torras, 1984: 116-117, 1985: 157-158; C. Manera, 1988 a). 
por 100) y Santanyí (2,54 por 100). La fabricación y distribución de licor proporciona a estas poblaciones la posibilidad de integrarse en los circuitos comerciales, y una razón para obtener mayores ingresos si se comparan a otras zonas que sustentan una agricultura encaminada al autoconsumo. Sin embargo, éste no es el único factor que justifica, por ejemplo, el que Felanitx alcance uno de los niveles salariales más elevados de Mallorca; también resalta la dedicación a actividades textiles.

2. La producción de tejidos de lino y cáñamo para un consumo básicamente local. El número de telares de lino y cáñamo existente es contradictorio, e indica una aparente recesión de la actividad manufacturera que debe matizarse, dado que las cifras oscilan entre los 94 para 1784, 77 en 1794,

\section{Comercialización de aguardiente}

(Porcentajes de cantidades en los mercados interior y exterior, según el lugar de fabricación, 1783-1788)

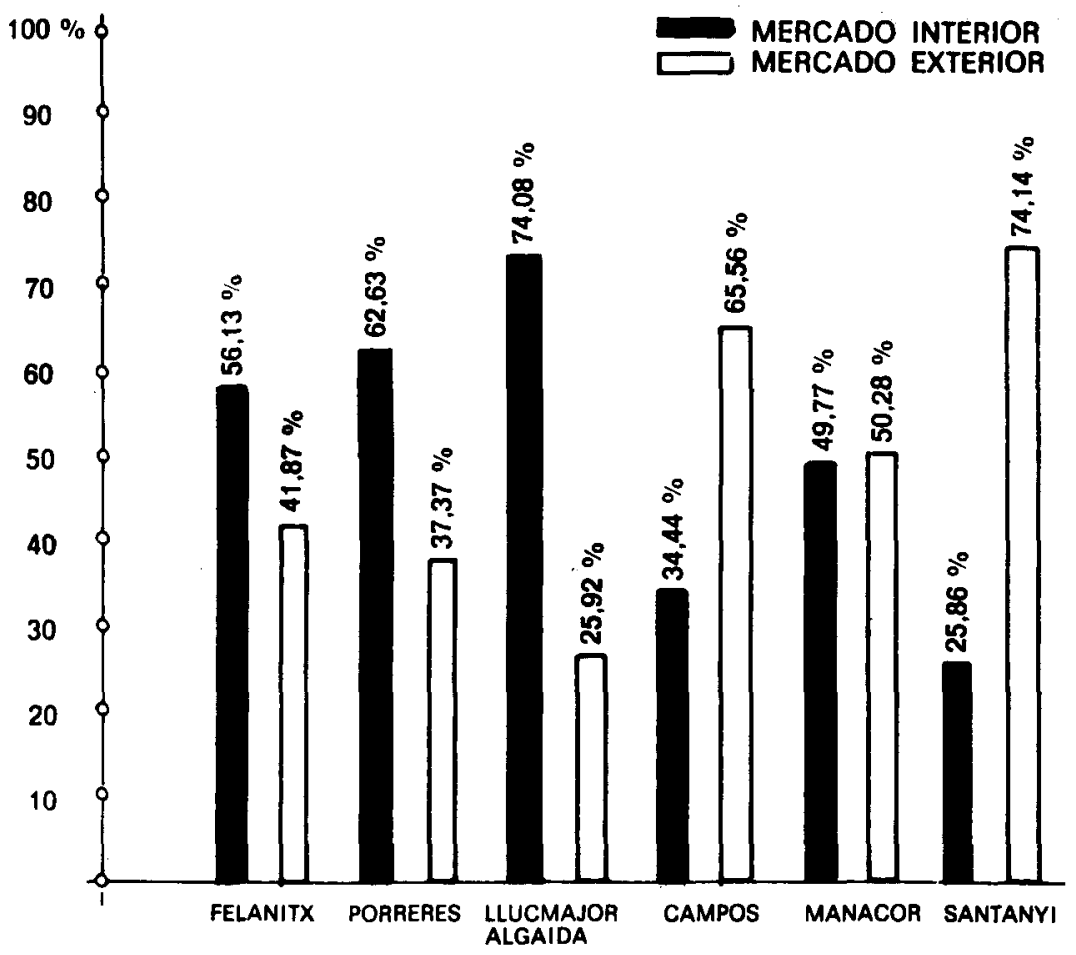


Exportaciones de aguardiente, 1783-1788.

Procedencia de las cantidades extraídas del Puerto de Palma

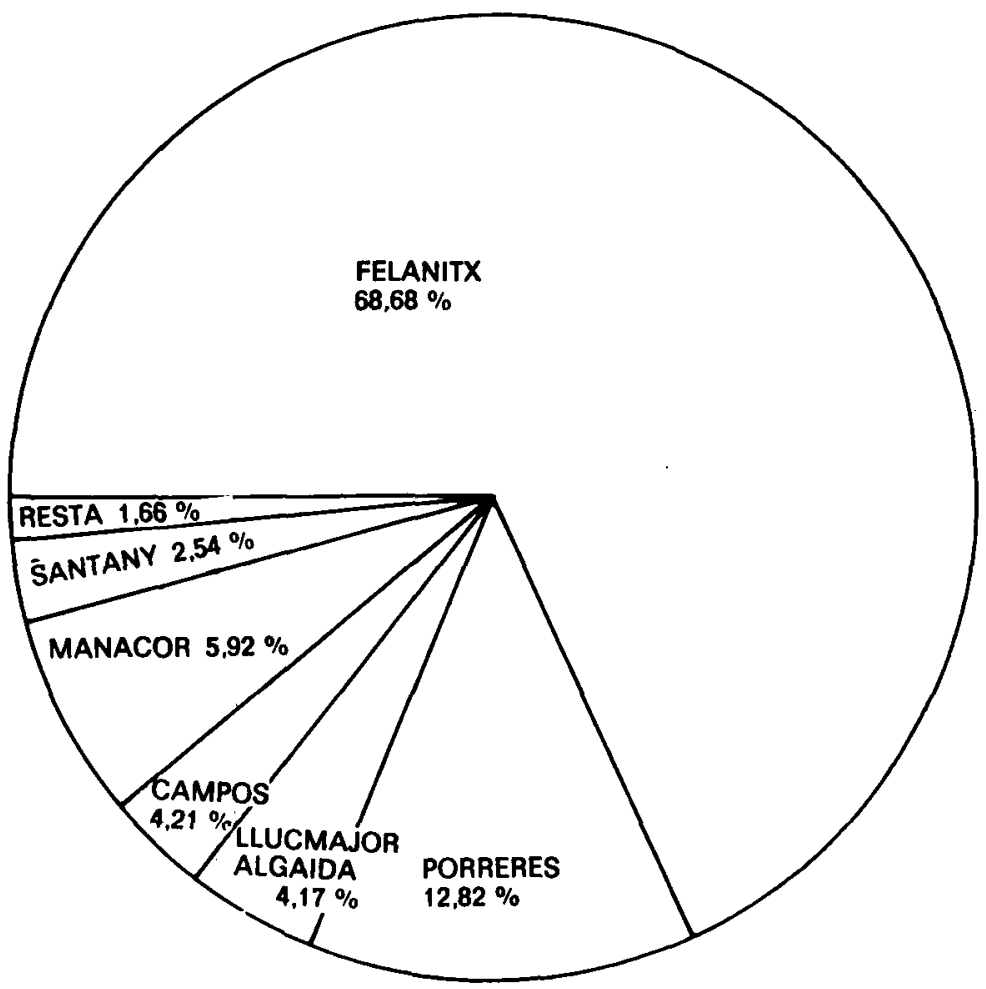

40 en 1800 y 26 en 1801 . De momento se ignora el motivo de la «desaparición» de 14 telares en un año, hecho que autoriza a desconfiar de variables tan irregulares; un factor importante lo confirma: las necesidades de materias primas. En 1801 se precisan 300 quintales de lino y 1.500 de cáñamo, cantidades elevadas para ser trabajadas sólo por los 26 telares correspondientes a dicho año, toda vez que un telar consume normalmente 11 quintales de cáñamo y cinco de lino ${ }^{24}$; por otra parte, los datos anteriores señalan que Felanitx requiere casi el 22 por 100 de la cosecha mallorquina de lino y cámaño -mientras que la producción de la villa se sitúa en torno a los 30 quintales-, porcentaje muy alto, difícil de adjudicar al reducido número de telares censados. Los tejidos que se fabrican — "para los payeses del campo»- son lienzos blancos de lino y cáñamo con mezcla de algodón, y se

24 ARM, SEMAP, caja 27, expediente núm. 4. 
colocan principalmente en el mercado local. Con todo, si se asevera que las variables oficiales pecan por defecto, resulta también problemático pensar que la producción de los telares - que a nivel de hipótesis podrían ser entre 65 y 100 - sea absorbida únicamente por la demanda «doméstica», sin negociarse en otras poblaciones insulares e incluso en los mercados exteriores. Este trabajo manufacturero complementa las labores agrícolas, y es desarrollado esencialmente por pequeños propietarios, ya que «poseyendo algunas porciones de tierras que por si mismos cultivan, quando se ocupan en esto no pueden exercer su officio" ${ }^{25}$.

Pero el caso de Felanitx no es único: la conjunción entre especialización agrícola y manufactura textil es evidente en las poblaciones que progresivamente se dedican a la viticultura, como se demuestra en las matrices de correlación calculadas. Los datos correspondientes a los cinco municipios más importantes en cuanto a su producción vitícola e infraestructura textil (véase cuadro 5) denotan una clara correlación entre producción de vino y telares, cifra que se incrementa en el caso de alambiques-telares (es decir, hay mayor correlación entre las partes del capital fijo que entre este último y la fuerza de trabajo) y en el de producción de legumbres-tejedores, producción de aceite-tejedores y producción de aceite-producción de legumbres. Tales apreciaciones no difieren demasiado de las que pueden extraerse con un universo más amplio, con la ventaja de que los resultados son mucho más fidedignos, pues responden a la práctica totalidad del agro mallorquín (consúltese cuadro 6). Las razones son varias. Primeramente, la especialización textil se produce en los pueblos que tienen un mayor número de habitantes; véanse los guarismos que detallan las correlaciones entre telares/tejedores y población. En segundo lugar, esos municipios dedicados al textil son los que disponen de una mayor infraestructura vitícola; la correlación entre alambiques y telares es importante, pero es más reducida entre producción de vino y telares y de escasa entidad entre alambiques y tejedores. Con ello, se ratifica la estrecha ligazón entre los diferentes elementos que integran el capital fijo, hecho que se refleja con mayor nitidez en la recta de regresión.

${ }^{25}$ Supra, nota 23. La complementariedad se señala cuando se dice que uen los días lluviosos se emplea la Gente en componer algunos menages de casa». En relación a la manufactura de lana, su significación es menor: el número de tejedores y pelaires oscila entre 4 y 8 , mientras la producción de la materia prima se eleva a 300 quintales anuales. Se testifica la participación de los mercaderes en la organización de la producción, al subrayarse que las "manufacturas no se trabajan por su cuenta [de los artesanos] sí pero de [quien] les entrega la Lana por sus artefactos». Durante el siglo xvi, la actividad manufacturera, básicamente ligada a la lana -se fabrican telas bastas: burells y estameñas-, ya era significativa, mientras el lino y el cáñamo se cultivaban en casi todos los predios isleños, si bien en pequeñas proporciones; en aquella época se advierten los inicios de la especialización vitícola. A esta coexistencia entre manufactura y viticultura se añade la presencia de la pequeña propiedad, como rasgo característico de la estructura de la propiedad (O. Vaquer, 1987: 248, 306-308, 345.346, 364-365). 


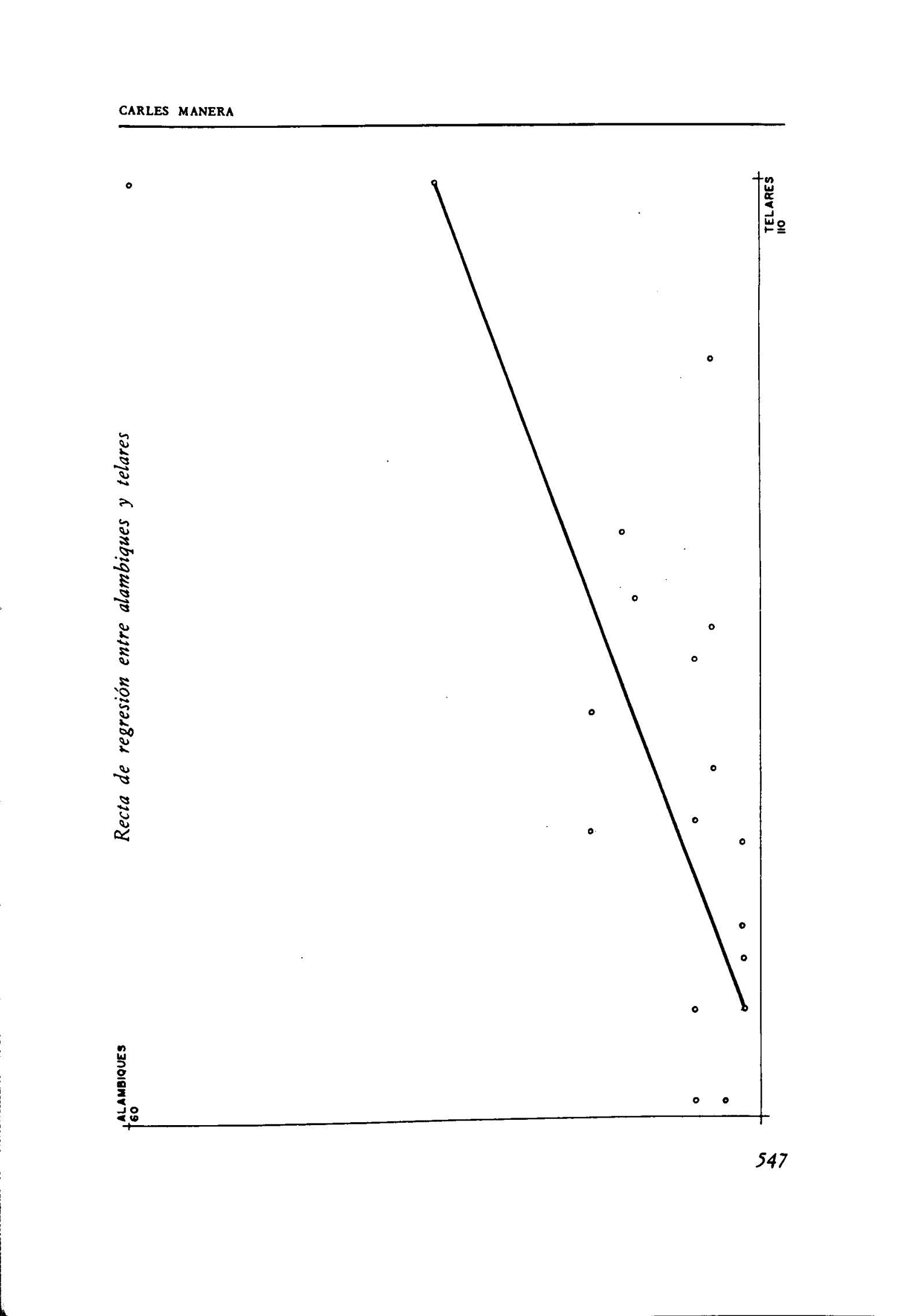




\section{Telares de lana y lino, 1784}
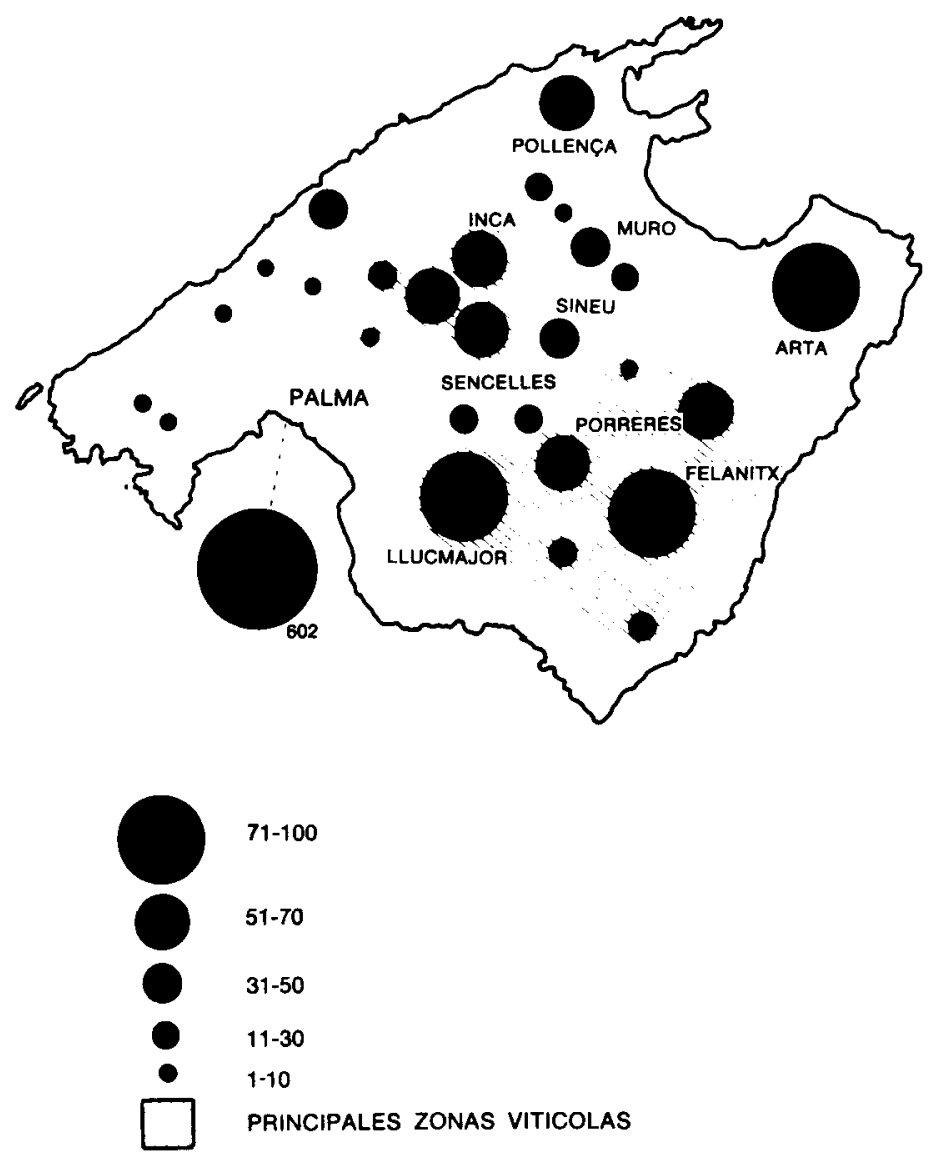

71-100

$51-70$

$31-50$

11-30

$1-10$

PRINCIPALES ZONAS VITICOLAS

En tercer término, resalta la variable producción de legumbres-tejedores, que insinúa una vinculación entre la industria textil y la existencia de una agricultura no extensiva que, en municipios concretos, podría ir ligada al regadío. Finalmente, las correlaciones negativas del aceite demuestran que estamos ante un producto que funciona con una lógica diferenciada, lo cual le excluye del resto de datos interrelacionados.

En definitiva, los municipios que tienen una mayor especialización «industrial» constatan al mismo tiempo una clara especialización en la agricultura intensiva; es decir, parecen disponer de una mayor diversificación económica, lo cual ayuda a explicar su concentración demográfica. Esta espe- 


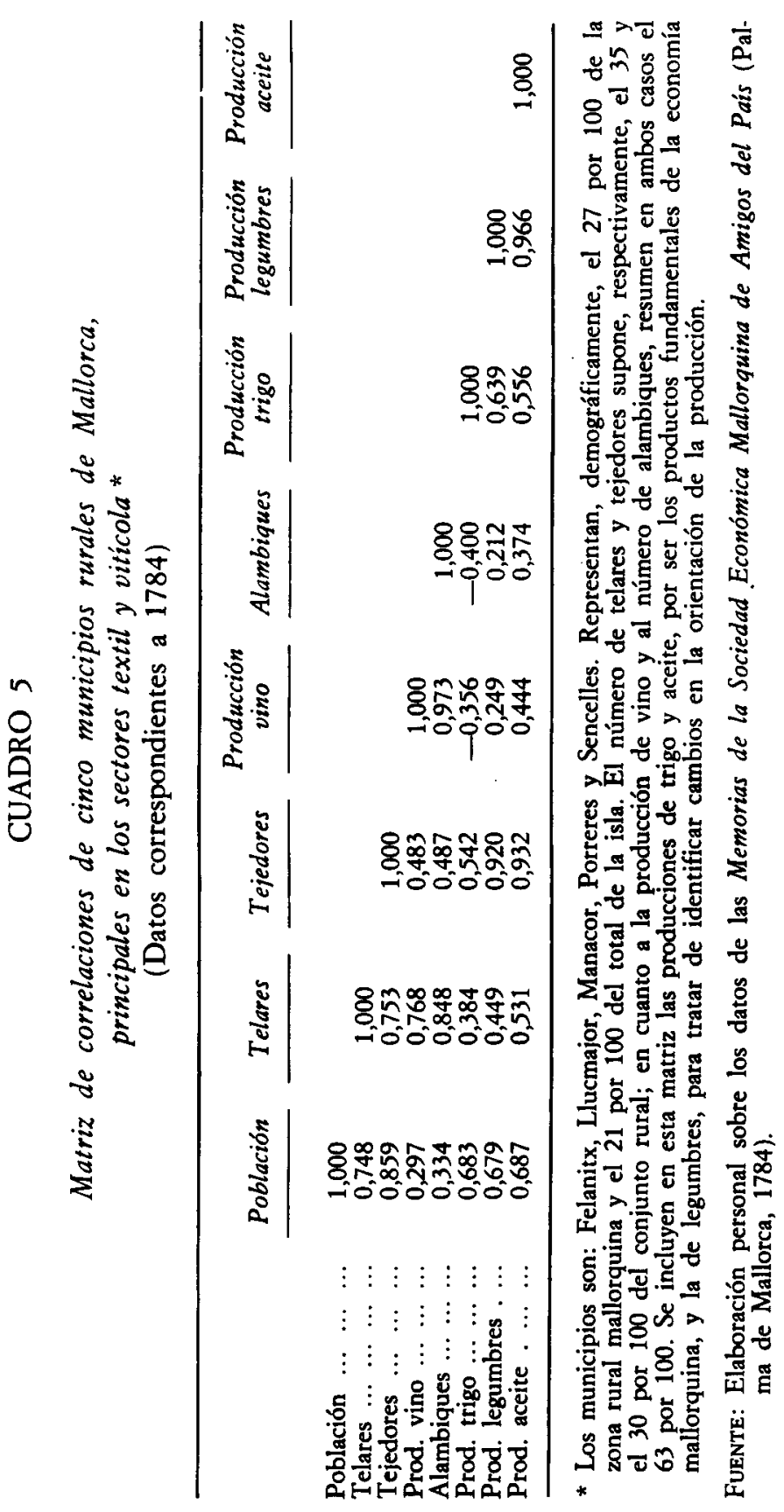




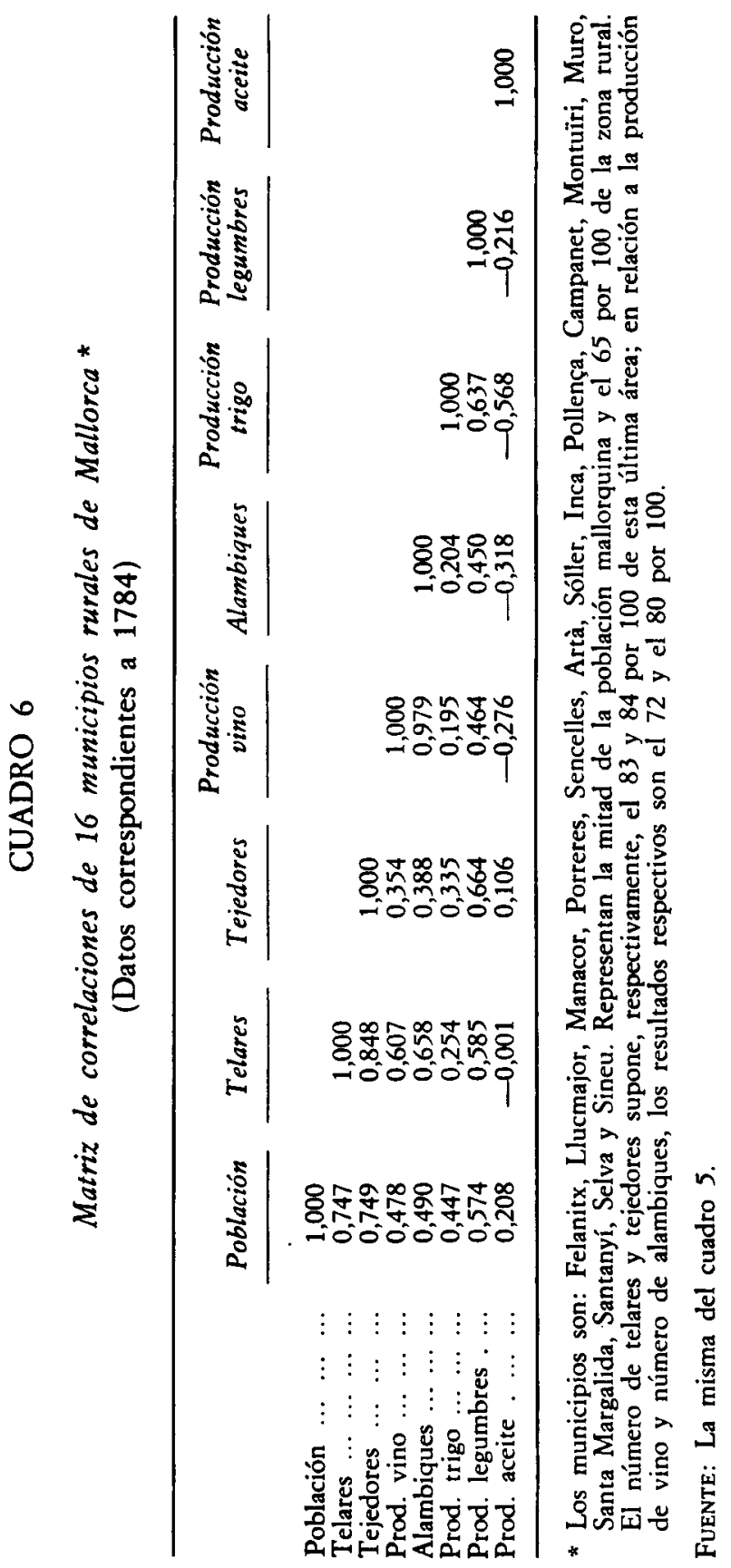


cialización tiene indicadores muy claros en las producciones absolutas de vino $\mathrm{y}$ en el número de alambiques, cifras que, como se ha visto, no se contraponen a las de los telares y los tejedores. Felanitx es la primera población productora de vino, a la vez que la que cuenta con más telares y alambiques (110 y 60 , respectivamente); le siguen Artá (91/4), Llucmajor (74/12), Manacor (67/11), Pollença (64/4), Inca (61/5), Sencelles $(55 / 15)$, Sineu (50/4), Muro (44/5) y Porreres (43/15). Estos centros ostentan además la mayor polarización de telares por artesanos dedicados al trabajo del lino -la media rural es de 1,37-, con la única excepción de Manacor; Felanitx, 1,69; Porreres, 2,15; Sencelles, 1,83; Llucmajor, 1,90.

\section{Recapitulación}

Las cifras comerciales registran una expresión indirecta del estado manufacturero de Mallorca. Con ellas, se certifica la presencia, significativa, de textiles locales en las exportaciones, mientras las importaciones enuncian compras de los factores de producción necesarios para el funcionamiento de la manufactura. Ambos capítulos constituyen valores que, si bien son distantes de las grandes magnitudes oleícolas y frumentarias, no son menospreciables, y esconden realidades socioeconómicas que urge estudiar con mayor profundidad. Se desvela, pues, la relevancia de actividades no agrarias que también deben analizarse como mecanismos de resistencia, al facilitar ingresos adicionales a los sectores sociales más empobrecidos. Dicho de otro modo, se acentúa la trascendencia de este tipo de labores desde la óptica microeconómica de su peso en las economías familiares de los campesinos, que además de los quehaceres textiles cuentan - fundamentalmente en determinadas zonas que en su conjunto suponen más del 30 por 100 de la población mallorquina- con otro tipo de recursos derivados de la progresiva especialización en su producción agrícola (cítricos, viticultura). En tal sentido, no es aventurado relacionar la manufactura textil con ciertas transformaciones econónicas de las áreas en cuestión, ya que contrastan con los rasgos conocidos en el resto de la isla. Esos cambios pueden resumirse en cuatro puntos: a) comportamiento demográfico diferenciado, $b$ ) incremento de la capacidad adquisitiva dado el mayor nivel salarial, $c$ ) diversificación de la producción, y d) existencia significativa de la pequeña propiedad.

$\mathrm{La}$ industria rural puede crear contradicciones al sistema establecido; pero es obvio que esas pequeñas fisuras no han sido abiertas por los grupos dominantes, principales interesados en que las reglas del juego no se trastoquen. El capital comercial realiza un papel significativo como organizador económico de la fuerza de trabajo; él tiene una cuota no desdeñable de res- 
ponsabilidad en las variaciones que se apuntan en la estructura económica isleña. En la manufactura, por ejemplo, el planteamiento de los mercaderes elude los límites marcados por los gremios. Entre otras acciones, especulan con las materias primas y en ocasiones las monopolizan, a la vez que integran mano de obra femenina y corporativa en las distintas fases de la producción textil, dificultando así la base productiva gremial. En definitiva, se articula una compleja red que impulsa el trabajo libre. Al mismo tiempo, el capital mercantil actúa como intermediario de las manufacturas textiles exógenas -de calidad superior a las locales-, de forma que contribuye al carácter subordinado de la producción autóctona.

La cuestión que se plantea es por qué esta industria, controlada esencialmente por los comerciantes, no propició procesos más «modernos» de concentración; es decir, no generó los mecanismos socioeconómicos pertinentes para su desarrollo posterior. El comportamiento económico de los grandes cargadores ofrece algunas pautas interpretativas. Las inversiones en tierras de las firmas más destacadas en el ámbito mercantil insular responden a la principal pretensión - nada novedosa- de estos nuevos ricos, empresarios industriales en potencia: integrarse en los círculos sociales privilegiados ${ }^{26}$. Los recursos susceptibles de inversión en infraestructuras manufactureras se encauzan hacia la posesión de predios, que el comerciante explota con similares criterios a los aplicados por la aristocracia. La seguridad de la renta de la tierra, frente a los inestables beneficios comerciales, y el prestigio social que ello reporta, justifican en parte esta estrategia. Sin embargo, surge otro interrogante: si la industria rural es tan significativa, y los comerciantes colocan sus capitales en los sectores que presentan mejores expectativas, ¿por qué no invierten más en la manufactura? Una posible respuesta es que los textiles mallorquines tienen una fuerte competencia exterior, sobre todo en los mercados internacionales, que disponen de ofertas más solventes y variadas. Los destinos de las manufacturas insulares son el mercado local, el regional y el litoral peninsular, donde se compite con géneros de baja calidad, de forma que el sector mantiene unas reducidas posibilidades especulativas.

En definitiva, el estado de la manufactura en los primeros años del Ochocientos varía poco porque el capital comercial más poderoso, el más capacitado económicamente para financiar proyectos ambiciosos, es consciente

${ }^{26}$ Se conocen multitud de casos parecidos, cuya exposición bibliográfica alargaría excesivamente esta nota. Baste con recordar el ejemplo de Francia, estudiado por E. Labrousse, que, en cierta medida, caracteriza a los otros. Los empresarios galos llegan a ser prudentes terratenientes, más preocupados por consolidarse como propietarios de tierras y llevar una vida señorial; desde una óptica económica, esta actitud se traduce en toda una filosofía: nada de cambios en los mecanismos económicos fundamentales (E. Labrousse, 1970: 562 563). En una línea muy teórica - pero que plantea pocas cosas nuevas-, véase el reciente trabajo de I. Wallerstein (1988) sobre el paso del burgués a los círculos aristocráticos. 
de las limitaciones de una producción que se asienta sobre una infraestructura apta para avituallar la demanda existente. La industria rural se conserva, por tanto, en manos de los pequeños negociantes, bajo una estrategia de dispersión del proceso productivo, siguiendo así planteamientos ya conocidos en épocas anteriores.

\section{BIBLIOGRAFIA}

Alonso PÉrez, M. (1986): «Relaciones comerciales entre Mallorca y los puertos del sur de Francia al final del Antiguo Régimen», IV Jornades d'Estudis Històrics Locals, Palma de Mallorca, pp. 69-82.

ARchiduque Luis Salvador (reedición de 1984): Las Baleares descritas por la palabra y el dibujo, Palma de Mallorca.

BaIroch, P. (1988): «L'urbanisation des sociétés traditionnelles: xinème-xviIIème sjècle», texto multicopiado presentado en la Ventesima Settimana di Studio del Istituto Internazionale di Storia Economica «Francesco Datini», sobre el tema Metodi, risultati e prospetsive della storia economica, secc. XIII-XVIII.

Bernat, M. (1985): "Telers i teixidors a Mallorca. Apunts per a un estudi etnogràfic", Llum d'Encrucia. Estudis d'Etnologia, núm. 3, $37 \mathrm{pp}$.

- (1986): "L'obratge de la llana e ils "Capítols" del Rei Sanxo. Una hipòtesi de treball», Bolletí de la Societat Arqueològica Lul-liana, núm. 840, pp. 63-79.

Berg, M. (1987): La era de las manufacturas, 1700-1820, Barcelona, Crítica.

Boulanger, P. (1986): «Marsella $i$ el comerc dels olis de les Balears al segle XVIII», IV Jornades d'Estudis Historics Locals, Palma de Mallorca, pp. 59-69.

Braun, R. (1978): "Early industrialization and demographic change in the Canton of Zurich», en Ch. TILly (ed.), Historical Studies of Changing Fertility, Princeton, pp. 289-334.

Carbonero, M.* A. (1978): «Estructura territorial del sòl urbà», en R. Pié (ed.), Estudi sobre les parcel-lacions, assentaments i nuclis de població en el sòl urbanitzable i no urbanitzable, Palma de Mallorca, pp. 49-66.

Carmona, X. (1984): «Clases sociales, estructuras agrarias e industria rural doméstica en Galicia», Revista de Historia Económica, núm. 3, pp. 35-50.

Céla Conde, C. (1979); Capitalismo y campesinado en la isla de Mallorca, Madrid, Siglo XXI.

ChASSAGNE, S. (1981): «Aspectes des phènomenes d'industrialisation et désindustrialisation dans les campagnes françaises au xixème siècle», Revue du Nord, núm. 248.

Dagron, G. (1985): «Constantinoble: espai geogràfic, polític i social», L'Avenç, núm. 84, pp. 10-13.

Davíu, G. (1983): “La producció d'oli a Mallorca, segle xvirI. Aproximació en base a la documentació fiscal», I Col-loqui d'História Agrària, Valencia, pp. 391-410.

Delgado, J. M. (1987): "Política fiscal y asignación de recursos en la Monarquía borbónica», Manuscrits. Revista d'Història Moderna, núms. 4-5, pp. 25-40.

DE VRIES, J. (1982): La economía de Europa en un periodo de crisis, 1600-1750, Madrid, Cátedra.

- (1987): La urbanización de Europa, 1500-1800, Barcelona, Crítica.

DEYA, M. (1987): Gremios rurales $e$ industria precapitalista en Mallorca durante el siglo XVIII: la manufactura textil (tesis de licenciatura inédita), Universitat de les Illes Balears. 
FERnÁNDEZ DE Pinedo, E. (1980): «Manufacturas y artesanado», en M. TUÑón dE LARA (dir.), Historia de España. Centralismo, Ilustración y agonia del Antiguo Régimen (1715-1833), Barcelona, Labor.

Ferrer, L1. (1986): Els orígens de la industrialització a la Catalunya central, Barcelona.

Galasso, G. (1985): «Una capital i el seu regne: Nàpols», L'Avenç, núm. 82, pp. 22-27.

Gambi, L. (1985): «Camins i ciutats a la plana del Po», L'Avenc, núm. 87, pp. 12.18.

KRIEDTE, P. (1987): «La ciudad en el proceso de protoindustrialización europea», Manuscrits. Revista de Història Moderna, núms. 4-5, pp. 171-208.

Kriedte, P.; Medick, H., y Sс нulmboн м, J. (1986): Industrialización antes de la industrialización, Barcelona, Crítica.

LABRousse, E. (1970): «Les ruptures périodiques de la prospérité: crisis économiques du xvinème sièclem, en VV. AA., Histoire économique et social de la France, París.

Llopis, E. (1986): "¿Los siglos XVIII en España o las Españas del Setecientos?», Revista DE Historia ECONÓmiCA, núm. 3, pp. 589-608.

MaDoz, P. (1848): Diccionario geográfico-bistórico de España y sus posesiones, Madrid.

Maluquer dE Motes, J. (1985): «Barcelona: una ciutat, una regió, un Estat», L'Aveņ, núm. 81 , pp. 18-22.

MANERA, C. (1984): «Aportación al estudio del problema cerealícola en Mallorca a fines del xviII: las gratificaciones a la introducción de trigo», Bolletí de la Societat Arqueològica Lul-liana, núm. 838 , pp. 273-296.

- (1988 a): «Viticultura i mercat. Reflexions sobre la producció i el tràfic de l'aiguardent mallorquí durant el segle xviri», Estudis d'Història Econòmica, núm. 1, pp. 117-151.

- (1988 b): Comerç $i$ capital mercantil a Mallorca, 1704-1800, Palma de Mallorca, Consell Insular de Mallorca.

- $(1988 \mathrm{c})$ : «Comerç, capital mercantil i manufactura textil a Mallorca», Randa, núm. 23.

Martínez Shaw, C. (1980): «La fabricació de l'aiguardent», L'Avenç, núm. 32, pp. 38-44.

MENDELS, F. (1986): "Agricultura e industria rural en el Flandes del siglo xviII", en P. Kriedte, H. Medick y J. SC нulmbo H M, Industrialización antes de la industrialización, Barcelona, Crítica, pp. 241-265.

Merrington, J. (1982): «Ciudad y campo en la transición al capitalismo», en R. HiLTON (ed.), La transición del feudalismo al capitalismo, Barcelona, Crítica, pp. 238-276.

Moll, I.; Segura, A., y Suau, J. (1983): Cronología de les crisis demogrâfiques a Mallorca, segles XVIII-XIX, Palma de Mallorca.

Moll, I., y Suau, J. (1979): «Senyors i pagesos a Mallorca (1718-1860/70)», Estudis d'História Agrària, núm. 2, pp. 95-170.

- (1985): «Memoria explicativa del estado de la isla de Mallorca en el siglo xvim», en R. Fernández (ed.), España en el siglo XVIII. Homenaje a Pierre Vilar, Barcelona, Crítica, pp. 249.288.

MorI, G. (1976): Studi di storia dell'industria, Roma, Riuniti.

- (1978): La nascità dell'industria, Florencia, Le Monier.

- (1983): La Revolución industrial, Barcelona, Crítica.

Nell, E. (1984): Historia y teoría económica, Barcelona, Crítica.

PonI, C. (1985): «Protoindustrialization, Rural and Urban», Review, IX, pp. 305-314.

Riera Melis, A. (1986): La Corona de Aragón y el Reino de Mallorca en el primer cuarto del siglo XIV, Madrid-Barcelona.

Rosselló Verger, V. M. (1982): "Canvis de propietat i parcel-lacions al camp mallorquí entre els segles XIX i XX», Randa, núm. 12, pp. 19-60.

Roura, Ll. (1985): L'Antic Règim a Mallorca. Abast de la commoció dels anys 1808-1814, Palma de Mallorca.

Segura, A., y Suau, J. (1981): «Aproximació a l'estudi de la pagesia al primer terç del segle XIX», Bolleti de la Societat Arqueològica Lul liana, núm. 835, pp. 393-437.

- (1984): «Estudi de demografia mallorquina: l'evolució de la població», Randa, núm. 16, pp. 19-61.

Sevillano Colom, F. (1976): "Artesanía textil de la lana mallorquina (siglos xIv y xv)", en M. Spallanzani (ed.), Produzione, commercio e consumo dei panni di lana (sec. XII-XVIII), Prato-Florencia. 
Tilly, Ch. (1983): «Flows of capital and forms of industry in Europe, 1500-1900», Theory and Society, núm. 12, pp. 123-142.

- (1984): «Demographic origins of the European proletariatm, en D. Levine, Proletarization and Family History, Nueva York, Academic Press.

ThIRSK, J. (1988): «Specialization and diversification in the rural economy», texto multicopiado presentado en la Ventesima Settimana di Studio del Istituto Internazionale di Storia Economica "Francesco Datini», sobre el tema Metodi, risultati e prospettive della storia economica, secc. XIII-XVIII.

Torras, J. (1984): «Especialización agrícola e industria rural en Cataluña en el siglo XViII", Revista DE Historia ECONómICA, núm. 3, pp. 113-127.

- (1985): «Aguardiente y crisis rural (sobre la coyuntura viticola, 1793-1832)», en A. García Sanz y R. Garrabou (eds.), Historia agraria de la España contemporánea, Barcelona, Crítica, vol. I, pp. 151-173.

VAQUER, O. (1987): Una sociedad del Antiguo Régimen. Felanitx y Mallorca en el siglo XVI, Palma de Mallorca.

VIRRANKOSKI, P. (1963): «Replacement of flax by cotton in the domestic textile industry of South-West Finland», Scandinavian Economic History Review, núm. 11.

Wallerstein, I. (1988): "The Bourgeois (ie) as concept and reality», New Left Review, núm. 167, pp. 91-106.

WYROBISZ, A. (1986): "El comerç entre l'Europa central i l'àrea mediterrània», L'Avenç, núm. 99, pp. 6-13. 